CHRISTOPHER BOONE

Columbia University

ARINDRAJIT DUBE

University of Massachusetts, Amherst

ETHAN KAPLAN

University of Maryland, College Park

\title{
The Political Economy of Discretionary Spending: Evidence from the American Recovery and Reinvestment Act
}

\begin{abstract}
We study in this paper the spatial allocation of expenditures in the American Recovery and Reinvestment Act (ARRA), one of the largest discretionary funding bills in the history of the United States. Contrary to both evidence from previous fiscal stimulus programs and standard theories of legislative politics, we do not find evidence of substantial political targeting. The districts of party leaders did not receive more funds than those of rankand-file legislators, nor did the districts of pivotal voters in the Senate or swing voters in the House receive more money. While Democratic districts overall received more per resident than Republican districts, this differential nearly disappears when we consider award per worker in each district or when we control for district poverty rate. Democratic states did receive modestly greater funds, but this is largely due to higher levels of funding going to places with more generous state welfare programs. At the same time, we find no relationship between the amount awarded and measures of the severity of the downturn in the local economy, while we do find more funds flowing to districts with higher levels of economic activity and greater incidence of poverty. The results are consistent with the discretionary component of ARRA being allocated through funding formulas or based on project characteristics other than countercyclical efficacy or political expediency, which stands in contrast to evidence from fiscal stimulus in the New Deal. One explanation suggests that over the past century, legislative norms have reduced the scope of discretion-with attendant benefits and costs.
\end{abstract}


T he American Recovery and Reinvestment Act (ARRA) of 2009, otherwise known as the Obama stimulus bill, was one of the largest discretionary spending bills in U.S. history. At the time of its passage, it allocated a total of $\$ 787$ billion, consisting of $\$ 212$ billion in tax cuts, $\$ 267$ billion in entitlement programs, and $\$ 308$ billion in discretionary projects awarded through contracts, grants, and loans. Passed during the Great Recession, the stated aim of ARRA was to appropriate funds "for job preservation and creation, infrastructure investment, energy efficiency and science, assistance to the unemployed, and State and local fiscal stabilization." In his remarks during the bill signing, President Obama emphasized the multiplicity of the mandate to create jobs and to do so by pursuing high-quality projects:

What makes this recovery plan so important is not just that it will create or save three and a half million jobs over the next two years, including nearly 60,000 in Colorado. It's that we are putting Americans to work doing the work that America needs done in critical areas that have been neglected for too long-work that will bring real and lasting change for generations to come. ${ }^{2}$

In other words, the purpose of the act was to stimulate the economy, provide assistance to the unemployed, and expand provision of high-quality public goods. In this broad panoply of goals, the most important was to provide economic stimulus using fiscal policy. In the words of then House Minority Leader John Boehner, "The president made clear when we started this process that this was about jobs. Jobs. Jobs. Jobs." ${ }^{\prime 3}$ In fact, the bill became popularly known as the "Obama stimulus bill," emphasizing its goals for recovery.

In this paper, we study the allocation of the funds in ARRA, with an eye toward several objectives. First, given the bill's size and significance, understanding how and where the money was spent is important in and of itself. Second, we use this bill to test theories from political economy in order to learn about the legislative process and the distribution of government spending in general. Finally, ARRA provides an opportunity to examine the political economy of a particular type of government spending-namely, fiscal policy for the purpose of macroeconomic stabilization — and in doing so, we consider the implications for improving the design of such policies.

1. Quoted from the ARRA Preamble. The full text of the bill may be found at http:// www.gpo.gov/fdsys/pkg/BILLS-111hr1enr/pdf/BILLS-111hr1enr.pdf.

2. New York Times, February 17, 2009 (http://www.nytimes.com/2009/02/17/world/ americas/17iht-17textobama.20261060.html).

3. Quoted in "Recovery Bill Gets Final Approval," New York Times, February 13, 2009 (http://www.nytimes.com/2009/02/14/us/politics/14web-stim.html). 
Two prior papers have also looked at the distribution of funds in ARRA. Robert Inman (2010) conducts a state-level analysis and finds that funding formulas explain most of the cross-state variation. We conduct a similar analysis and find similar results at the state level, but we find that different funding formula variables matter at the district level. James Gimpel, Frances Lee, and Rebecca Thorpe (2013) conduct a county-level analysis and find no role for the unemployment rate in the allocation of funds across counties. Our study is more comprehensive than either of these two, and our analysis focuses on the district level, which is not covered in either.

There are a number of competing views about how funds would be distributed in actual practice. One view, consistent with the administration's stated goal of providing stimulus, is that the geographic distribution of expenditures would reflect the economic evidence on fiscal multipliers. Recent evidence suggests that state and local multipliers are larger in areas with greater excess capacity (Dube, Kaplan, and Zipperer 2014; Nakamura and Steinsson 2014; Shoag 2010). Thus, we might expect funds to be targeted toward areas that were more heavily exposed to the economic downturn-for example, areas with larger increases in unemployment. In addition, David Johnson, Jonathan Parker, and Nicholas Souleles (2006) document that individuals with low levels of income and low levels of liquidity respond more strongly to stimulus. We might therefore expect areas with higher levels of unemployment or higher rates of poverty to receive more money, due to the belief that targeting transfers toward these individuals would lead to higher multipliers and more job creation.

An alternative view of the stimulus bill is that it would be filled with pork barrel projects. Less than two weeks before the signing of the bill, the future head of the House budget committee, Representative Paul Ryan, referred to the bill as a "bloated porkfest" in an interview with the conservative news agency, Newsmax. ${ }^{4}$ This view was widely reported in much of the mainstream press, including $\mathrm{CNN}^{5}$ and the Washington Post. ${ }^{6}$ The view of the stimulus bill as pork-laden is still common today. Edward Krosner, former editor of Newsweek, New York magazine, Esquire, and the New York Daily News, wrote in a 2014 Wall Street Journal op-ed, "Mr. Obama repeated

4. "'Porkfest' Will Crush Economy, Rep. Ryan Says," Newsmax, February 10, 2009 (http://www.newsmax.com/RonaldKessler/Obama-stimulus-pork/2009/02/10/id/328187/).

5. "What GOP Leaders Deem Wasteful in Senate Stimulus Bill," CNN, February 4, 2009 (http://www.cnn.com/2009/POLITICS/02/02/gop.stimulus.worries/index.html).

6. "Despite Pledges, Stimulus Has Some Pork," Washington Post, February 13, 2009 (http:// www.washingtonpost.com/wp-dyn/content/article/2009/02/12/AR2009021203502.html). 
the rookie mistake he made with the stimulus bill, which became a bloated porkfest."

The political economy literature provides further predictions about the pattern of spending. One theory is that politicians act in the interests of their party. Therefore, we might expect to see parties directing funds toward marginal districts in order to improve the electoral success of the party. However, there is a long-standing literature in political science suggesting that the United States, having a majoritarian political system, has weak political parties (Baron 1991; Shor 2006a; McCarty, Poole, and Rosenthal 2001). Indeed, using a regression discontinuity design, David Albouy (2013) finds that states where a majority of congressional districts are aligned with the party of the president receive a relatively small and statistically insignificant 2.6 percent more in intergovernmental transfers from the federal government relative to states where a majority of congressional districts are aligned with the opposite party. Boris Shor (2006a; 2006b) finds similar results for the allocation of funds in state legislatures. In contrast, using less well identified but more representative panel methods, Christopher Berry, Barry Burden, and William Howell (2010) find that counties whose congressional representative is aligned with the party of the president do receive more funds.

Another theory posits that politicians are self-interested and maximize their own return without strong regard to either the general welfare or party interests. In this case, districts with powerful politicians should receive more discretionary funds. Both Brian Knight (2005) and Gary Cox, Thad Kousser, and Matthew McCubbins (2010) provide empirical evidence that those with agenda-setting power are able to gain substantial rents. In contrast, Berry, Burden, and Howell (2010), using a 23-year panel of county-level disbursements of federal government expenditures, find that committee leaders and members of important committees do not receive greater amounts of federal dollars per capita than other districts.

Similarly, it may be that political moderates who can credibly threaten to vote for either side receive more funds for their districts. The most commonly used model in political economy, the probabilistic voting model (Lindbeck and Weibull 1987), captures this intuition. It shows that policy and rents are apportioned to individuals in rough proportion to their probability of being swing voters. Such rent accrual to ideological moderates has been verified in the Swedish context (Dahlberg and Johansson 2002).

7. “Obama the Management Failure,” Wall Street Journal, January 8, 2014 (http://online. wsj.com/news/articles/SB10001424052702303933104579302480571979884). 
In the context of ARRA, we might expect senators and representatives with more moderate voting records, as well as members who are seen as pivotal for this particular vote, to receive greater funds.

In our paper, we look at the distribution of funds both across states and across congressional districts, and we examine how the allocation of funds was related to both the economic characteristics of the local area as well as the political characteristics of the area's congressional representatives. The geographic pattern of ARRA spending turns out to be generally inconsistent with most of the above predictions. When it comes to the economic determinants of stimulus, we find no significant correlation between the amount spent and the local unemployment rate, suggesting that the funds were not spatially targeted so as to maximize the fiscal multiplier. We do find, however, that congressional districts with higher percentages of the population under the federal poverty line received a greater amount of funding. Finally, we also find that congressional districts with greater employment-per-resident (that is, central urban and more economically active areas) received substantially more funding. At the same time, these district-level findings for poverty and employment are not replicated at the state level; in fact, states with higher rates of poverty received somewhat smaller amounts of funding, suggesting that the targeting to poor areas happened at the level of allocations within states and not across states. This is consistent with the ARRA budgeting process, whereby a certain portion of funds allocated to a state were "set aside" for particular areas or purposes.

We divide our results on political targeting into whether individuals were targeted and whether groups (political parties) were targeted. For the former, we test whether members of Congress were able to secure more funds for their districts by exploiting their positions of power within Congress, for example through formal leadership positions or through their status as pivotal members. For the latter, we examine whether politicians influenced the allocation of funds in order to benefit one political party over the other.

Individual targeting does not appear to have played a role in the allocation of funds. We find no evidence that powerful members of Congress were able to secure more funding for their districts; this includes party leaders as well as Democratic and Republican committee leaders. In contrast to Matz Dahlberg and Eva Johansson (2002), we find that ideological moderates were actually less likely to receive ARRA funds. We also find no evidence that pivotal legislators received substantially more funds. This is not surprising in the House, where the bill was certain to pass due to the large 
majority held by the Democratic party at the time. However, it is somewhat surprising that it was also true in the Senate, where the Democratic Party needed a minimum of two Republican votes to avoid a filibuster.

It is important to note that our finding that pivotal members of the Senate did not receive more funds is consistent with academic and popular accounts that pivotal members had large influence over the bill. Nolan McCarty, Keith Poole, and Howard Rosenthal (2013) discuss press reports about the senators from Maine using their pivotal status to reduce the size of the bill by $\$ 200$ billion and to adjust the Alternative Minimum Tax for inflation, while Republican Senator Arlen Specter of Pennsylvania used his clout to increase funding for the National Institutes of Health. We have no way to test for the impact of pivotal senators on the overall composition of the bill, but we find no evidence that pivotal senators increased the amount of funds allocated to their home states. We interpret these results as showing that politics did not affect the geographic distribution of funds. However, this should not be construed as implying that the politics or political ideology of powerful legislators did not influence the bill.

While we see no evidence of targeting toward individual politicians, the evidence on group targeting (that is, partisanship) is more mixed. In general, our evidence supports the weak-party hypothesis. Importantly, neither of the two parties appears to have targeted extra funds toward marginal districts, that is, those that had close outcomes in the previous election. Likewise, we find no significant impact of being a marginal Democrat versus a marginal Republican. This is an important result for two reasons. First, legislators working in the interests of the party might choose to target funds toward marginal districts, because these are the districts most vulnerable to switching parties in the next election. Second, close Democratic districts and close Republican districts are likely to be similar along many other dimensions as well, so this comparison offers the cleanest empirical test of whether districts were targeted based on their explicit party affiliation. Our results here echo those of Albouy (2009), although in contrast to the literature, we focus on a single piece of legislation; nonetheless, the legislation we analyze is sizable, with $\$ 308$ billion in highly discretionary funds. Notably, Albouy (2009) finds his null results during a time of divided government (1980-2003) during which several presidents all had to bargain with Congress in order to get legislation passed, while we find the same null effect during a period of strong unified government. We also look at the state-level allocations and consider whether swing states in the electoral college received more money, and we find that this is not the case; if anything, swing states receive less funding. 
At the same time, we do find some evidence suggesting that strongly Democratic areas received slightly higher levels of funding, although we are unable to determine whether this reflects targeting for partisan political purposes or merely reflects the policy preferences of the politicians who wrote the bill. In our baseline sample, which excludes state capitals, Democratic districts in the House received, on average, only \$95 more per capita in discretionary funding than their Republican counterparts, despite the fact that Democrats had large majorities in both chambers of Congress and held the presidency at the time of ARRA's passage. Controlling for district characteristics that were relevant for some of the funding formulas, this differential falls to $\$ 34$ per capita and is not statistically significant. In addition, we do not find any differential by party when we consider award per worker (as opposed to per resident) in the districts-with or without controls. We do find that strongly Democratic districts, those where the Democratic Party vote share is 80 to 90 percent, received more funds. However, this differential is at least partly driven by a small number of very dense urban districts with high levels of employment—and the differential is smaller when we consider the stimulus award per worker in the district. Thus, it may reflect dollars going where firms are located. Our results for the House of Representatives are echoed in the Senate: we find that states with more Democratic senators received more money.

Overall, when we consider the variation in spending across congressional districts and states, we do not find much evidence of targeting based on either countercyclical or political considerations. It is possible that Democrats felt constrained in their ability to explicitly target districts based on partisan affiliation, yet they still engaged in a more subtle form of targeting; they may have targeted based on characteristics such as employment and poverty, precisely because those characteristics tend to be associated with Democratic districts. Another possibility is that the policy preferences of Democratic legislators support the types of projects that tend to be located in Democratic constituencies. While we can rule out more explicit measures of partisan targeting, we are not able to identify or distinguish between these more subtle and limited forms. However, the evidence generally suggests that both economic and political targeting was limited.

The relative lack of political and countercyclical targeting in the most discretionary components of ARRA contrasts with evidence from New Deal legislation. Price Fishback, Shawn Kantor, and John Wallis (2003) argue that grants under the New Deal were targeted both to high unemployment areas and to swing district supporters of President Franklin Roosevelt in the prior presidential campaign. In section IV of this paper, where we interpret 
our results, we consider some possible explanations for this difference. In particular, we argue that since the 1930s, bills have increasingly relied on funding formulas. In the case of ARRA, we find that the amount of money spent is highly correlated with employment and poverty, both of which are featured heavily in the formula language in the bill. Others have argued that these funding formulas were enacted primarily to facilitate quick disbursement of funds while limiting pork. However, even funding formulas can be altered to benefit certain districts over others, allowing legislators to funnel large sums of money to their districts. Thus, we also argue that shifts in norms have put additional constraints on today's bills to spread benefits relatively evenly across districts. This hypothesis is borne out in our results, since we find that after removing from the analysis seven districts with large projects, funding is spread relatively evenly across districts.

Some caution is warranted when drawing general conclusions from our results. First, it is worth recalling that ARRA was passed by a new president, one who had spoken out against pork and in favor of government transparency. Moreover, the losing candidate in the recent presidential election had strongly advocated for abolishing earmarks (targeted geographical expenditures). Thus, from an early stage, the president had announced that he would not accept a bill with earmarks. Second, President Obama had run for office promising a post-partisan administration. Therefore, the White House was plausibly concerned about appearing overly partisan by spending money in a politically targeted way. Third, the bill was passed at the height of employment losses during the Great Recession, and thus there was a shared sense of urgency for the bill across the Democratic Party. Finally, the bill was all but guaranteed passage in the House, although it needed a few Republicans to avoid a filibuster in the Senate.

These caveats notwithstanding, we believe our study offers some general lessons. First, we note that it is often the case that bills are marginal in the Senate but assured to pass or fail in the House. This is due to the Senate's filibuster rule, whose use has been increasingly common in recent years. Second, the urgency of the bill, though perhaps uncommon for a general spending bill, is probably not uncommon for a stimulus bill, since the onset of large recessions is usually rapid. Therefore, our study is likely to be relevant for understanding the political economy of fiscal stimulus. Third, our results are consistent with those from the burgeoning empirical political economy literature on distributive politics.

The remainder of the paper is structured as follows. In section I, we summarize how decisions were made to allocate ARRA funds. In section II, we describe the data that we use. In section III we present our results, and 
in section IV we interpret the findings and discuss policy implications. Section V concludes.

\section{How Congress Budgeted ARRA}

In Congress, budget items are normally sent through fiscal committees as well as appropriations committees in both the House and the Senate. This was also true in the case of ARRA. Most of the details of the contracts, grants, and loans (hereafter CGL) portion of the bill were decided in the 12 appropriations subcommittees in the House and the Senate.

Since both the Obama administration and leaders in the Republican Party had argued strongly against expenditures being explicitly targeted to particular districts, no earmarks were incorporated into the bill. Before the bill was passed, each of the 12 appropriations subcommittees, separately in both the House and the Senate, came up with proposed budgets. These budgets were then reconciled across the House and the Senate and the resulting compromise was ultimately written into the bill. Since it was clear early on both that no Republican House members would vote for the bill (as none actually did) and that Republican votes would not be needed, Republicans in the House of Representatives played little role in formulating the budget. In the Senate, all of the Democrats who were present voted in favor of the bill; they were joined by two independents who caucused with the Democrats: Senator Joe Lieberman of Connecticut and Senator Bernie Sanders of Vermont. ${ }^{8}$ In addition, one Democratic senator, Ben Nelson of Nebraska, publicly announced his ambivalence about the bill in the weeks leading up to the vote. The Democrats and independents were joined by three Republican senators: Susan Collins and Olympia Snowe, both from Maine, and Arlen Specter, from Pennsylvania. ${ }^{9}$ Thus, Republicans played a larger role in the Senate than in the House, but the bill was still predominantly formulated by congressional staff on the Democratic side.

The bill was crafted with strong time constraints that, combined with the desire to eliminate pork, led the appropriations committees to provide funding using pre-existing federal formulas. Some of the project money was allocated through competitive grants so that at least some projects were selected based solely on project quality. Thus, almost all of the CGL money was allocated using either funding formulas or competitive grants.

8. Senator Ted Kennedy (D-Mass.) did not vote, due to illness, and Senator Al Franken (D-Minn.) was not allowed to sit for the Senate seat until the summer of 2009 due to litigation following a very close election.

9. Specter was a Republican until May 2009, when he switched to the Democratic Party. 
A hard commitment to pre-existing formulas would in theory reduce the rent-seeking behavior of politicians to simply bargaining for general increases in levels of funding through particular formulas, in lieu of particular projects for their districts or states. However, incentives to argue for marginal increases in formula funding are muted, because in most formulas an increase of one dollar in funding to a legislator's constituents would be accompanied by an increase of tens of dollars to other states and an increase of hundreds of dollars to other districts. This point is well argued by Michael Grunwald (2012, p. 233) who relates the following:

The final spat on the Senate side did not pit the moderates against the leadership, but Specter against Ben Nelson, who wanted to tweak the Recovery Act's formula for distributing Medicaid funds to get rural states extra cash. Specter said: No way. [Peter] Orszag did some calculations in his head, and informed Rahm [Emanuel] that Nelson was hijacking the entire stimulus over $\$ 25$ million.

It is unclear precisely how the commitment to use historical funding formulas was maintained. We suggest the possibility that legislative norms or norms among voters can sustain this commitment and, moreover, that this allows for both contemporaneous improvements in avoiding wasteful bargaining or graft as well as increased reciprocity between legislators over time.

The ARRA formula money was disbursed by federal agencies and given to state governors. However, gubernatorial discretion was limited regarding how it could be spent, where it could be spent, and how quickly it could be spent. For example, highway money had to be used to build and repair highways only, 50 percent of it had to be spent within 6 months, and all of it had to be spent within a year. Any money that remained unspent was to be redistributed to other states by the Federal Department of Transportation. Other portions of the bill mandated that a certain percentage of the funds be spent in rural or urban areas.

The competitive grant money was allocated to the executive branch agencies and was then allocated to recipients based on merit using criteria described in the bill. The criteria used by the various departments differed by type of grant and were written by both legislators and staffers.

Despite the pervasive use of funding formulas and competitive grants, there was still room for substantial political influence over the distribution of expenditures. The Obama administration pushed for certain projects that were of interest to it (including money for alternative energy, highspeed rail, and local public transportation). Similarly, whereas pushing for district-specific projects was not allowed, members of Congress could have influence over how much money their districts received by putting more 
money into programs that favored their districts or states or by altering funding formulas or program criteria. For example, members of Congress from rural areas might have tried to push the subcommittees to increase allotments to funding formulas based on highway miles, while representatives from urban districts might have pushed for increased funds through funding formulas for public transportation systems. Overall, despite the pervasive use of funding formulas and competitive bidding, there was indeed substantial scope for politicians to affect the geographical distribution of funds.

\section{Data Description}

In this section we detail the sources used in our analyses of the data.

\section{II.A. American Recovery and Reinvestment Act of 2009}

Our data on ARRA spending come from the website www.recovery.gov, which was created to provide taxpayers with information on how the ARRA funds were spent, as mandated by the Act itself. Spending under ARRA can be divided into three major categories: tax benefits; entitlements; and contracts, grants, and loans (CGL). For the last category, Recovery.gov provides information on each individual recipient, including the recipient's address, along with the primary zip code and congressional district where the activity was to be carried out. For the tax benefits and entitlements categories, only state-level statistics are available. A majority of the analysis in this paper is therefore focused exclusively on the CGL funds. Some of our state-level analysis uses aggregated data at the state level, which also include most of the entitlement spending.

As of January 2014, the total estimated expenditure under ARRA was $\$ 840$ billion (an increase from the original estimate of $\$ 787$ billion). Of this total, CGL funds accounted for around $\$ 267$ billion. We aggregate the amount of disbursement to the House district level and, for some specifications, to the state level.

We exclude from our baseline district-level analysis all congressional districts containing any part of a state capital. We do this because a large portion of the money sent to state capital districts was disbursed to the state governments and subsequently redistributed across the state. For example, educational grants are predominantly sent to state capitals and then distributed by governors and state legislatures throughout the state. The ARRA data record this type of spending as going to the congressional district where the headquarters of the state governmental agency is located, and therefore the data do not accurately reflect the distribution of spending across 
congressional districts. After dropping congressional districts containing any part of a state capital, we are left with 334 out of 435 congressional districts, implying that the average capital city is contained within two congressional districts. We discuss this issue in more detail below. Overall, $\$ 106$ billion of the $\$ 267$ billion in CGL funds remains after excluding state capitals from the sample.

For our state-level analysis, in some specifications we aggregate the CGL data to the state level. For other specifications, we use aggregate state-level data reported by the federal agencies and available through Recovery.gov. These agency-reported data include contracts, grants, and loans as well as some of the entitlement money, such as unemployment insurance and Medicaid funds.

\section{II.B. Voting and Congressional Data}

We use vote returns reported in Congressional Quarterly for the November 2008 general election for the U.S. House of Representatives. The twoparty Democratic vote share in each congressional district is computed as the number of votes for the Democratic candidate divided by the total votes for the Democratic and Republican candidates. The median Democratic vote share in our sample is 57.7 percent, reflecting the Democratic majority in the House at the time. On February 13, 2009-the date of the vote on the ARRA conference report-there were 255 Democrats, 178 Republicans, and 2 vacant seats in the House of Representatives. We also obtain from Congressional Quarterly the average Democratic vote share for president at the state level.

Data on the tenure of each member of the House come from the Office of the Clerk of the House of Representatives, and data on the tenure of senators come from Roll Call, the newspaper published by Congressional Quarterly. We use data from the website Govtrack.us to track committee assignments for the 111th Congress and each representative's vote on ARRA. DW-Nominate scores for individual legislators were downloaded from voteview.com.

\section{II.C. Other Data}

We also use data for a number of demographic and economic characteristics at the state and district levels. Data on state-level Medicaid and county-level unemployment insurance expenditure are from the Bureau of Economic Analysis. District-level information on population, poverty, and land area comes from the U.S. Census Bureau. We use data on county-level unemployment rates from the Local Area Unemployment Statistics program 
at the Bureau of Labor Statistics. County-level information on home loans is from Home Mortgage Disclosure Act (HMDA) data, made available by the Federal Financial Institutions Examination Council. District-level characteristics for unemployment rate, home loans, highway miles, and unemployment insurance are derived from the county-level information using geographic correspondences provided by the Missouri Census Data Center. For data on total employment, we use the 2008 LEHD Origin-Destination Employment Statistics (LODES) data available from the U.S. Census Bureau and aggregate the census block-level data to the district level. ${ }^{10}$

\section{Results}

In this section, we present our main results. We begin by looking at how the ARRA money was distributed across different types of expenditures. In section III.B, we discuss the correlation of expenditures with economic variables. In section III.C, we test for targeting to the Democratic Party. In section III.D, we test for individual targeting of powerful political elites. In the final portion of the results section, we test for targeting of pivotal members of Congress as well as party defiers.

In each of the following sections, we separately discuss evidence from the Senate and the House of Representatives. On the one hand, the Senate seems a more natural place to look for the impact of politics on the allocation of funds, because it was in the Senate that passage of the bill was uncertain and a few swing legislators had the potential to influence the outcome. It is also possible that Senate leaders who negotiated the bill were better able to obtain political rents for their districts than House leaders were, since there was little need for internal bargaining in the House. A second advantage of looking at the Senate is that it allows us to view a larger fraction of the total ARRA expenditures. For example, the supplemental expenditures for entitlement programs, such as money for Medicaid expansion and unemployment insurance, are not reported at the congressional district level. Additionally, a large portion of the CGL funds were formally allocated to state capitals but in practice spread across districts within the states; we thus have to omit these state-level program expenditures in our district-level analysis.

On the other hand, the fact that passage of the bill was assured in the House certainly does not rule out targeting of funds to party leaders and wellconnected members of the House. The House still needed to be bargained

10. LODES data are not available for Massachusetts, so we instead use the ZIP Code Business Patterns from the U.S. Census Bureau, and derive district-level employment using geographic correspondences from the Missouri Census Data Center. 
with, and House leaders could have exploited their agenda-setting power. In addition, since ARRA was passed only by Democrats in the House, it is possible that partisan effects could have been much stronger across House districts than across states. Another important difference between the House and the Senate is in the number of representatives. There are 435 House districts, 334 of which did not contain any portion of a state capital. Therefore, there are almost seven times as many observations when looking at House districts as compared to looking at the states represented in the Senate, and thus the House affords us a substantially larger sample size. Finally, since the Senate contains two members per state while the House contains only one member per district, we might expect stronger individual targeting in the Senate but stronger group targeting in the House. In this paper, therefore, we look at the allocation of funds across states as well as across congressional districts.

\section{III.A. What Was the Money Spent On?}

In this section, we give an overview of what types of projects were funded with the ARRA money. In online appendix figures A1 and A2, we display maps showing the amount of stimulus funds received, with darker areas indicating higher levels of funding per capita. ${ }^{11}$ Figure A1 shows per capita amounts at the state level, while figures A2a and A2b show amounts at the congressional district level. Figure A2b omits districts containing portions of state capitals and therefore displays the distribution of funding we use in our main district-level analysis. The maps reveal no immediately obvious patterns.

The mean amount of stimulus funds received per resident in a district in the form of CGL was $\$ 469$ (or $\$ 900$ per capita when including state capitals). State capitals receive substantially higher amounts per capita than noncapital districts because capital districts receive funds for state governments, particularly education funds, which constituted a very large proportion of total funds. The mean amount of CGL funds received per resident of a state was $\$ 517$, excluding state capitals (and $\$ 1,056$ including state capitals). The discrepancy between states and districts reflects the fact that smaller states received a higher average amount of funds per resident. The mean receipt of funds per resident in the agency data is $\$ 1,617$. This is substantially higher than the CGL data, because it includes money allocated to state-level programs such as unemployment insurance and Medicaid.

11. Online appendixes for all papers in this volume may be found at the Brookings Papers webpage, www.brookings.edu/bpea, under "Past Editions." 
Table 1. Descriptive Statistics ${ }^{\mathrm{a}}$

\begin{tabular}{|c|c|c|c|c|}
\hline & \multicolumn{2}{|c|}{ With state capitals } & \multicolumn{2}{|c|}{$\begin{array}{l}\text { Without state } \\
\text { capitals }\end{array}$} \\
\hline & Mean & $\begin{array}{l}\text { Standard } \\
\text { deviation }\end{array}$ & Mean & $\begin{array}{l}\text { Standard } \\
\text { deviation }\end{array}$ \\
\hline \multicolumn{5}{|l|}{ State level } \\
\hline CGL amount ${ }^{\mathrm{b}, \mathrm{c}}$ & 5,334 & 5,705 & 2,112 & 3,133 \\
\hline CGL amount per capita & 1,056 & 450 & 517 & 262 \\
\hline Agency-reported amount ${ }^{c}$ & 9,444 & 10,685 & & \\
\hline $\begin{array}{l}\text { Agency-reported amount } \\
\text { per capita }\end{array}$ & 1,617 & 429 & & \\
\hline $\begin{array}{l}\Delta \text { Unemployment rate } \\
\text { Jan 07-Jan } 09\end{array}$ & 2.96 & 1.25 & & \\
\hline Employment per resident ${ }^{\mathrm{d}}$ & 45 & 4.11 & & \\
\hline Poverty rate (percent) & 12.7 & 2.94 & & \\
\hline Medicaid per capita & 976 & 326 & & \\
\hline Interstate miles per capita & 0.00029 & 0.00035 & & \\
\hline State population (millions) & 6.13 & 6.8 & & \\
\hline $\begin{array}{l}\text { Average Senate Democratic } \\
\text { vote share (percent) }\end{array}$ & 52.4 & 13.9 & & \\
\hline \multicolumn{5}{|l|}{ District level $^{\mathrm{f}}$} \\
\hline CGL amount ${ }^{\mathrm{c}}$ & 613 & 1,213 & 316 & 370 \\
\hline CGL amount per capita & 900 & 1,786 & 469 & 543 \\
\hline Stimulus amount per worker & 1,941 & 3,623 & 1,101 & 1,308 \\
\hline Poverty rate (percent) & 13.4 & 5.56 & 13.6 & 5.83 \\
\hline Percent urban & 79 & 19.8 & 79.9 & 20.3 \\
\hline Land area (square miles) & 0.813 & 3.07 & 0.54 & 1.01 \\
\hline Total highway miles & 852 & 975 & 762 & 864 \\
\hline Employment ${ }^{\mathrm{g}}$ & 297 & 100 & 289 & 103 \\
\hline Percent spent in 1 year & 32.2 & 9.9 & 31.2 & 9.19 \\
\hline $\begin{array}{l}\text { House Democratic vote } \\
\text { share (percent) }\end{array}$ & 57.7 & 23.4 & 57.8 & 24.4 \\
\hline Tenure $^{\mathrm{h}}$ & 6.24 & 4.55 & 6.53 & 4.65 \\
\hline DW-Nominate score & -0.0336 & 0.441 & -0.0329 & 0.44 \\
\hline Total CGL amount & $\$ 267$ billion & & $\$ 106$ billion & \\
\hline $\begin{array}{l}\text { Total agency-reported } \\
\text { amount }\end{array}$ & $\$ 472$ billion & & & \\
\hline
\end{tabular}

a. All financial amounts in dollars unless otherwise indicated.

b. CGL amount refers to the ARRA funds received by the state or district in the form of contracts, grants, and loans.

c. Dollars in millions.

d. Employment per resident is calculated as total state employment divided by state population times 100 .

e. Medicaid per capita is based on Medicaid expenditure in 2005.

f. The district-level political variables (tenure, Democratic vote share, DW-Nominate score) refer to the House member representing that district.

g. In thousands of workers.

h. Number of 2-year terms. 
The descriptive statistics in table 1 show sizable variation in expenditure across congressional districts. The standard deviation of per capita expenditure is $\$ 543$ per person excluding state capitals (and $\$ 1,786$ per person including state capitals). We also report vote share information in table 1. Since the House of Representatives was highly Democratic at the time, the mean Democratic vote share was 58 percent. The vote share was identical for districts containing at least some portion of a state capital.

Focusing only on congressional districts outside of state capitals, we begin by showing a kernel density estimate of the per capita expenditure. ${ }^{12}$ The distribution, shown in figure 1 (upper panel), is heavily skewed to the right. The district that received the lowest amount of money was Representative Anthony Weiner's (Democratic) district in New York City, which received around $\$ 7$ per person of CGL funding. The highest amount received by any congressional district in our sample was around $\$ 3,750$ per person for Representative Doc Hastings' (Republican) district, which includes the Tri-Cities and Yakima, Washington. This means Hastings' district received over 500 times more money per person than Weiner's district. In the lower panel of figure 1, we show a histogram and kernel density estimates of the Democratic vote share. There are two modes of the distribution of vote share: one Republican mode around 40 percent and another Democratic mode around 70 percent. There are also a few districts with uncontested Republican winners and almost three times as many districts with uncontested Democratic ones.

Although the amount of variation across congressional districts was substantial, the amount of variation across states was much more muted. However, the large amount of variation across districts is largely driven by a small number of outliers. To show this, we decompose the sum of the squares of per capita funding into the mean and residual variation:

$$
\sum_{i=1}^{I} y^{2}=I \bar{y}^{2}+\sum_{i=1}^{I}\left(y_{i}-\bar{y}\right)^{2} .
$$

We report the mean fraction of the sum of squares (or one minus the residual variation share of the sum of squares):

$$
\frac{I \bar{y}^{2}}{\sum_{i=1}^{I} y_{i}^{2}}=1-\frac{\sum_{i=1}^{I}\left(y_{i}-\bar{y}\right)^{2}}{\sum_{i=1}^{I} y_{i}^{2}} .
$$

12. We use an Epanechnikov kernel with an optimal bandwidth minimizing mean squared integrable error relative to a fitted Gaussian distribution. 
Figure 1. Histograms of District-Level Stimulus Amount and Democratic Vote Share

Stimulus amount per resident ${ }^{\mathrm{b}}$

Number of districts

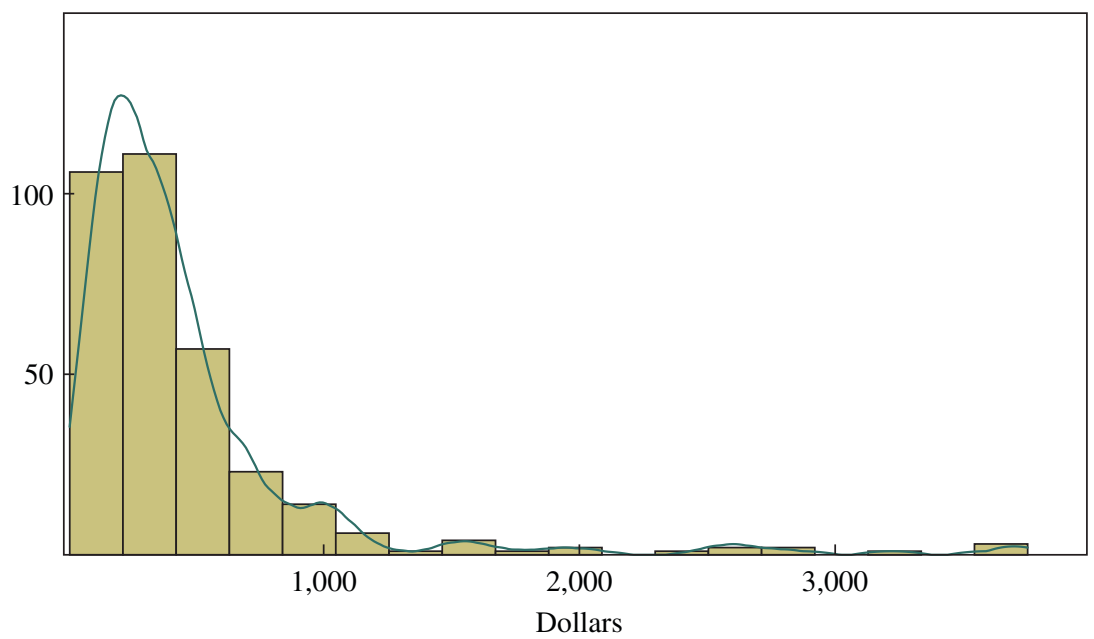

Democratic vote share ${ }^{\mathrm{c}}$

Number of districts

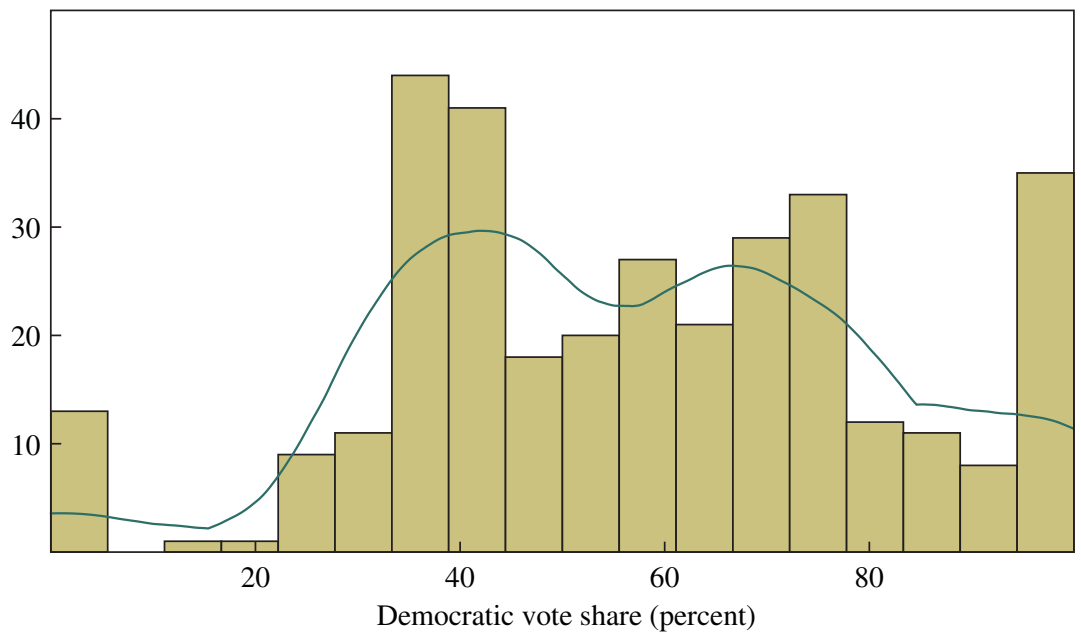

Source: Authors' calculations.

a. Sample includes the 334 districts not containing state capitals.

b. Stimulus data include only contract, grants, and loans reported on recovery.gov.

c. Democratic vote share is the percentage of Democratic votes out of total votes for the Democratic and Republican candidate in the 2008 congressional election. 
Overall, de-meaned cross-district variation accounts for 79.9 percent of the total sum of the squares of payments per resident in the CGL data. Thus, the mean payment to a district accounts for a mere 20.1 percent of the total sum of the squares.

This shows that ARRA expenditures were not distributed equally. However, when we omit state capitals, the portion attributable to the mean rises to 42.8 percent.

We then identify 17 outliers, using a cutoff of $\$ 1,300$ per resident. Of these districts, 12 are Democratic districts and five are Republican districts. Out of the 10 districts receiving more than $\$ 2,000$ per resident, five are Republican and five are Democratic. If we take a simple regression model with per capita funds on the left-hand side and only a constant term and Democratic dummy on the right-hand side, adding in dummies for these 17 districts increases the $R^{2}$ from 0.007 to 0.808 . Moreover, we find that the mean share of the sum of the squares rises to 68.5 percent.

When we look at the distribution of funds on a per-worker basis, we find five Republican districts and two Democratic ones that get more than $\$ 3,500$ per worker. In a simple regression with amount per worker on the left-hand side and only a constant term and Democratic dummy on the right-hand side, we obtain an $R^{2}$ of zero (to three significant digits). However, adding seven dummies for the outlier districts increases the $R^{2}$ to 76.4 percent. Taking out these seven outlier districts increases the mean share of the sum of the squares from 41.6 percent to 67.7 percent, which is very similar to the mean share in per-resident terms after removing the 17 top outliers. The state-level mean shares using the CGL data are significantly higher. Including the funds going to state capitals, the mean share is 79.9 percent. Omitting state capital funds, it rises to 84.9 percent. Using the agency data, it is 93.6 percent. This result shows that state shares of per capita expenditure did not vary much. We display the distribution of expenditures per resident as well as per worker, including the outliers, in figure 2.

The large amounts allocated to the outlier districts are due to sizable individual awards rather than to a large number of awards. We show these results in online appendix figure A3. The two top recipients among Republicans, Doc Hastings (Wash.) and Buck McKeon (Calif.), represented districts in which the largest awards made up 22 percent and 42 percent, respectively, of the district's fund allocation. In both cases, these were large competitive DOE grants or loans (water reclamation at the Hanford nuclear site and a solar energy loan, respectively). The two top recipients among Democratic-represented districts - the district of Elijah Cummings (Md.) and that of Barbara Lee (Calif.) — had 29 percent and 11 percent of their funds, 
Figure 2. District-Level Outliers

\section{Stimulus amount per resident}

Dollars

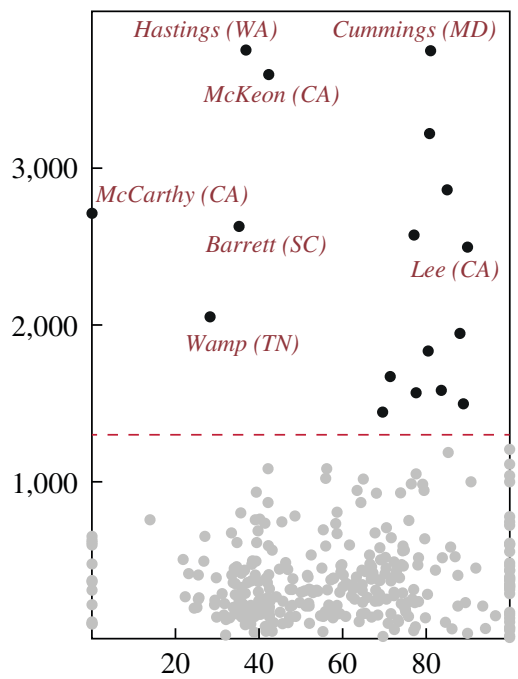

Democratic vote share (percent)
Stimulus amount per worker (dollars)

Dollars

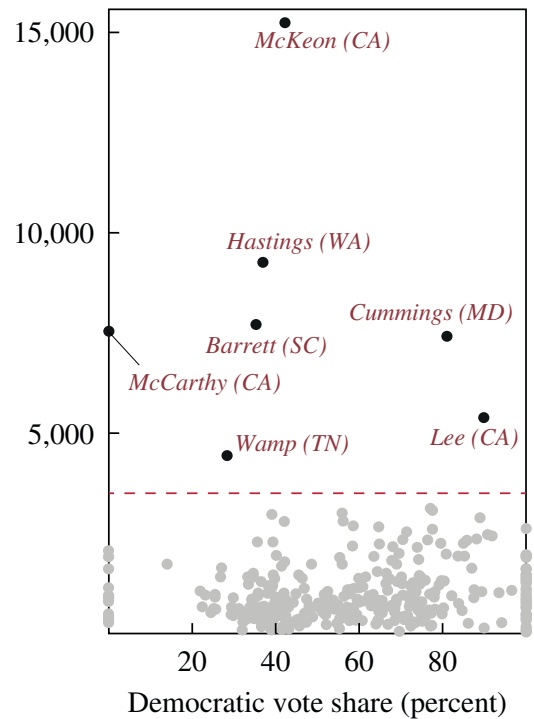

Source: Authors' calculations.

respectively, going to their top grant. In the case of Elijah Cummings' district, the funds were for the Maryland Department of Education; normally such funds would go to the state capital (Annapolis), but in this case they went to Baltimore..$^{13}$ In the case of Barbara Lee's district, the large grant was to the California Department of Transportation for the construction of a local highway tunnel.

More generally, the top ten recipients all received more than $\$ 2,000$ per recipient, and in every case a majority of the money was contained in the top 5 percent of grants. The top four recipients all received more than $\$ 3,000$ per resident, and more than 80 percent of their funds were in the top 5 percent of awards. In general, as seen in online appendix figure A3, there is a strong positive correlation between the amount a district received and the percent of funds received in the top 5 percent of awards. This suggests that outlier districts were outliers largely because they were awarded funding for particularly large projects, often through a competitive grant.

13. This is the only case we found where state funds went to a district that did not contain the state capital. 
The money in the ARRA bill was distributed through 207 different federal funding agencies. However, the top four (in funding amounts) of these accounted for 55 percent of the total CGL funds distributed. These four agencies are (in descending order): the Office of Elementary and Secondary Education ( $\$ 64.7$ billion), the Department of Energy ( $\$ 38.3$ billion), the Federal Highway Administration ( $\$ 27.9$ billion), and the Office of Special Education and Rehabilitation Services ( $\$ 13.6$ billion). The other top ten granting agencies (also in descending order) were the Department of Housing and Urban Development, the National Institutes of Health, the Federal Transit Administration, the Federal Railroad Administration, the Environmental Protection Agency, and the Rural Utility Service. These ten agencies distributed 74 percent of the $\$ 267$ billion in our data. The amounts for these top ten funding agencies are listed in online appendix table A1. The top five granting agencies in the data, excluding the state capitals, were the Department of Energy, the Federal Highway Administration, the National Institutes of Health, the Federal Transit Administration, and the Department of Housing and Urban Development (online appendix table A2).

\section{III.B. Economic Targeting}

Given the legislation's stated countercyclical objective, we now consider whether financial need or high excess capacity was predictive of how much funding a district received. In online appendix figure A4, we nonparametrically regress the amount received per resident on our two measures of excess capacity. In the left panel we measure excess capacity using the unemployment rate, and in the right panel we measure it using the change in the unemployment rate between January 2007 and January 2009. In both cases, we see that districts with higher unemployment received slightly less funding per district resident. These results reinforce similar findings by Gimpel, Lee, and Thorpe (2013) and Inman (2010). In the district-level regressions in table 2, we report coefficients on seven different variables for five specifications each, reflecting results from 35 different regressions in all. A constant term and (in some specifications) additional covariates are included in these regressions, but only the coefficient on the variable of interest is displayed. The top three rows report the results from regressions using CGL funds per district resident, and the bottom two rows report results using CGL funds per worker. We look at per-worker specifications because we do find that, in contrast to the crossstate variation, more money went to highly urbanized areas that were centers of employment. Much of the formula money given to the states stipulated that a certain percentage of the funds be spent in urban areas, so 


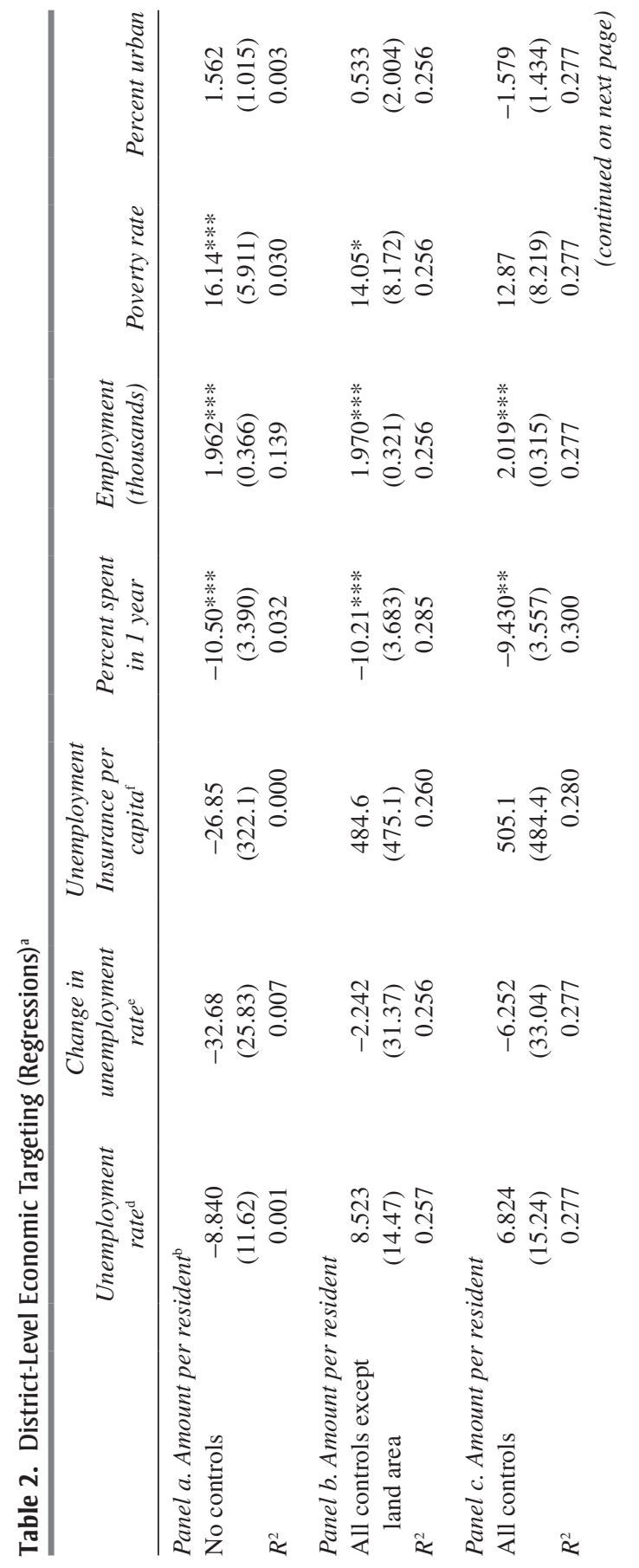




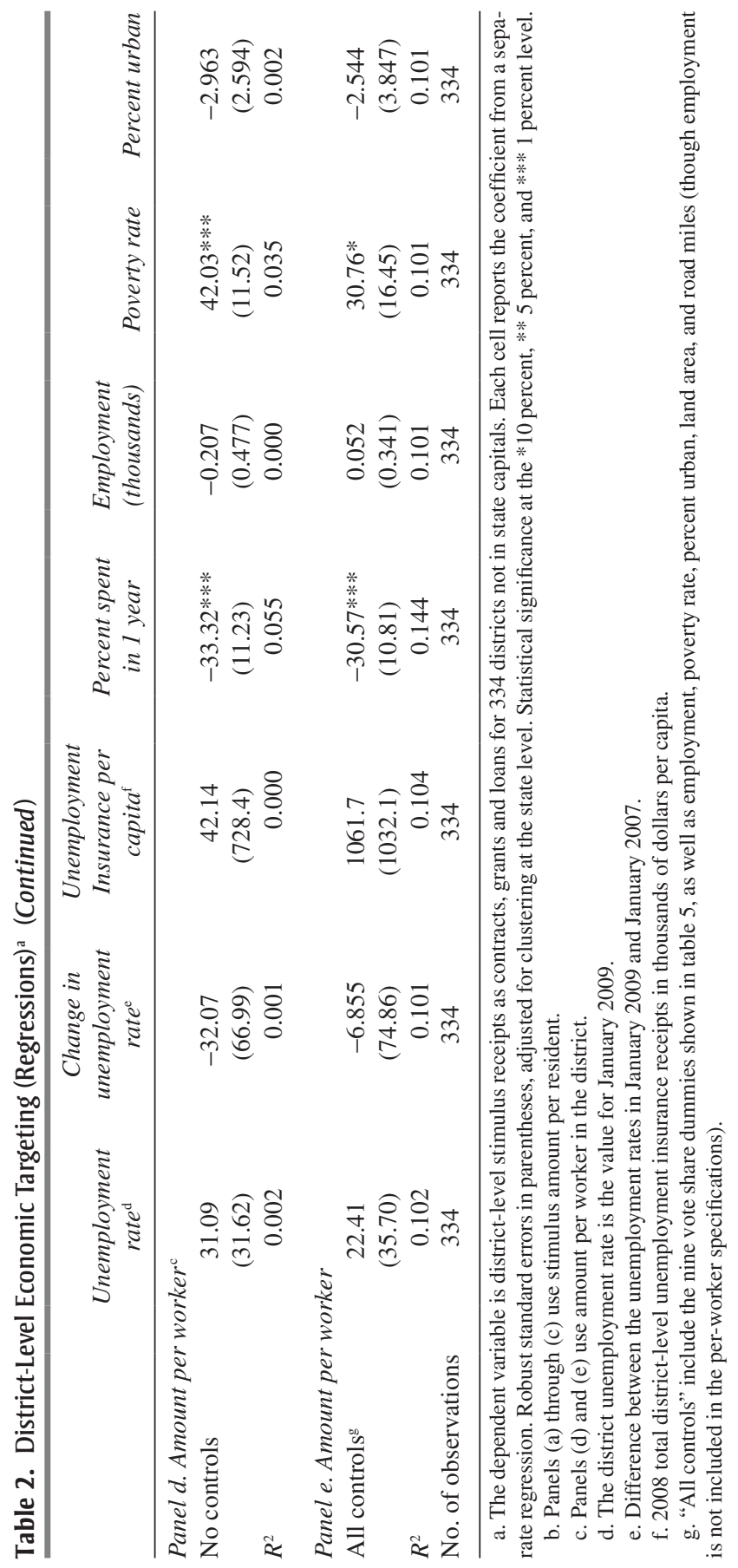


it is not surprising that the large-recipient districts were located in urban areas. At the same time, the districts that received the least amount of funding were also located in urban areas. Interestingly, the amount of funds received per resident is much more strongly correlated with employment in a district than with the percent of the district that is urban. Within large urban areas, there is substantial variation in employment levels across congressional districts.

Most people who work in Wyoming's congressional district also live in it. By contrast, a much lower percentage of people who work in the congressional districts in Manhattan also live there. Neighboring Brooklyn and Queens are much more places of consumption than production in comparison with both Manhattan and Wyoming. More CGL funds went to places like Manhattan with high levels of economic activity by firms or other recipient organizations than to places like Wyoming. Places like Wyoming, in turn, received more CGL funds than urban consumption centers like Brooklyn and Queens. This, in part, explains the low amounts of funding received by Representative Anthony Weiner's district (in Queens and Brooklyn). In the first and fourth rows of table 2, we show per resident and per worker results without any additional controls. In the second row we control for 2008 employment, the poverty rate, highway miles, and percent urban as well as nine vote-share bin dummies for the vote share of the congressional representative in the district. The results including all these covariates are generally statistically similar to the unconditional results. In the third row, we also control for land area. In some specifications, this leads to different results. All of these covariates represent variables that were explicitly or effectively incorporated into funding formulas. Finally, in the fifth row, we report the per-worker variant of the third row (omitting employment as a control). ${ }^{14}$

We find no statistically significant correlation in any of the specifications between amount per capita and either of our measures of unemployment or the per-resident amount of unemployment insurance spent in the district. We also find no statistically significant correlation with percent urban in any of the specifications. We do find very strong positive correlations between employment in a district and amounts per resident. The estimates are very tightly estimated. Districts with 100,000 more workers on average get \$200 more per resident. In all three per-resident specifications, the $t$ statistics are above 5 and the point estimates vary by less than 0.06 across specifications. Moreover, employment is not only highly correlated with

14. The coefficients on our additional controls are reported in online appendix table A3. 
funding, it is quantitatively important for explaining overall variation. Adding just employment increases the $R^{2}$ by almost 14 percentage points. No other variable in our district-level regressions has such large explanatory power. Also, adding in other controls does not change the marginal $R^{2}$ of adding in employment. The estimates are surprisingly invariant to controlling for percent urban. This is because urban areas have both places with very low employment per resident ratios, such as most residential districts in Brooklyn, as well as places with very high employment per resident ratios, such as the business districts in Manhattan. As a result, urbanness in itself is not highly correlated with employment per resident, nor is employment correlated with amount received per worker in the district.

The second most important of our covariates is poverty. Poor districts received more money. Adding in poverty increases the $R^{2}$ by approximately 0.03. Again, this is not surprising, given that some of the formula money set aside portions specifically for historically poor areas..$^{15}$ Nevertheless, the results on poverty are less robust than those on employment. Adding in our other controls lowers the coefficient estimates slightly but also almost doubles the standard errors. Unconditionally, places with a 1-percentagepoint higher poverty rate received $\$ 16$ more in funds per resident and $\$ 42$ more per worker. Since between one-third and one-half of the residents in a district work, ${ }^{16}$ the per-worker coefficients are usually two to three times as high. Unconditionally, both coefficients are significant at the 1 percent level. With the full set of controls, the $t$ statistics in the per-resident specification are just below significance at the 10 percent level with a $t$ statistic of 1.57, and the per-worker coefficient is significant between the 10 percent and the 5 percent level with a $t$ statistic of 1.87 .

One possible explanation for the lack of targeting to areas with high unemployment could be that ARRA was instead targeted to shovel-ready projects, and places with more shovel-ready projects could have been places with lower unemployment (or lower increases in unemployment). The Obama administration said that shovel-ready projects would be made a high priority, and this was reflected in the bill. Much of the formula grants stipulated that money would have to be returned if not spent quickly enough. While it is difficult to measure shovel-readiness using an ex-ante measure, we do have recipient-reported information on the pace at which the funds were

15. For example, some of the money disbursed by the Department of Labor used definitions of poor areas defined in a bill in 1965.

16. Note that this ratio is different from the employment-to-population ratio as usually defined in that it includes the elderly and children. 
disbursed and spent. To assess shovel-readiness, we construct measures of what fraction of the funds in a district were disbursed to projects that were completed within one year. Using this measure, we show (in online appendix figure A5) that places that were allocated more money were on average somewhat slower in completing projects. This is possibly because districts that received more money received money for large infrastructure projects, and these on average took longer. Nonetheless, as online appendix figure A5 shows uniformly, places that received more money did not complete their projects more quickly. And across all specifications in table 2, the coefficient on percent completed within one year is negative and significant at the 5 percent level or less. Moreover, in unreported regressions, we note that controlling for percent of funds spent within one year does not impact the coefficients on unemployment. In sum, though shovel-readiness may have played a role in the selection of projects, we find no evidence that it influenced how money was allocated across congressional districts.

We now consider the state-level results on economic targeting displayed in table 3 . We show the coefficient estimates for the change in the unemployment rate between January 2009 and January 2007; in the specifications with controls, we include the ratio of state employment to state total population, the poverty rate, Medicaid expenditures per capita, interstate highway miles, and the average Democratic vote share for the two senators serving terms in 2009. The specification is rather sparse because of the limited degrees of freedom with only 50 observations. This obviously also limits our ability to interpret our results. We show results for four different specifications: the agency data without controls, the agency data with controls, the CGL data including funds sent to state capitals, and the CGL data removing the funds that went to state capitals. We include controls in both of our CGL specifications. Even without controls, the change in the unemployment rate only adds 0.015 percentage point to the $R^{2}$. In contrast, adding our other five controls raises the $R^{2}$ to 0.436 . In none of the specifications does the coefficient on change in unemployment come close to statistical significance at conventional levels. The results using the agency data are particularly surprising, since those data include the federal provisions for state unemployment insurance programs and aid to state Medicaid programs that was explicitly targeted to states with above-median unemployment rates. ${ }^{17}$

17. When we examine only the funding distributed by the Department of Labor, which was largely for unemployment insurance, we unsurprisingly find that areas with higher unemployment received more money. 
Table 3. State-Level Economic Targeting (Regressions) ${ }^{\mathrm{a}}$

\begin{tabular}{|c|c|c|c|}
\hline & $\begin{array}{c}\text { Change in } \\
\text { unemployment }^{\mathrm{b}}\end{array}$ & $\begin{array}{c}\text { State } \\
\text { employment }^{\mathrm{c}}\end{array}$ & $\begin{array}{l}\text { Percent } \\
\text { poverty }\end{array}$ \\
\hline \multicolumn{4}{|c|}{ Panel a. Amount per resident: Agency-reported } \\
\hline \multirow[t]{2}{*}{ No controls } & -42.60 & $18.31 *$ & $-48.28 *$ \\
\hline & $(40.38)$ & $(10.49)$ & $(25.20)$ \\
\hline$R^{2}$ & 0.015 & 0.031 & 0.110 \\
\hline No. of observations & 50 & 50 & 50 \\
\hline \multicolumn{4}{|c|}{ Panel b. Amount per resident: Agency-reported } \\
\hline \multirow[t]{2}{*}{ With controls ${ }^{\mathrm{d}}$} & -7.591 & -30.79 & $-66.69 *$ \\
\hline & $(65.92)$ & $(20.68)$ & $(37.15)$ \\
\hline$R^{2}$ & 0.436 & 0.436 & 0.436 \\
\hline No. of observations & 50 & 50 & 50 \\
\hline \multicolumn{4}{|c|}{ Panel c. Amount per resident: Contracts, grants, loans } \\
\hline With controls ${ }^{\mathrm{d}}$ & $\begin{array}{c}-18.45 \\
(42.83)\end{array}$ & $\begin{array}{l}-41.32 * * \\
(18.91)\end{array}$ & $\begin{array}{l}-49.55^{* *} \\
(22.54)\end{array}$ \\
\hline$R^{2}$ & 0.683 & 0.681 & 0.681 \\
\hline No. of observations & 50 & 50 & 50 \\
\hline \multicolumn{4}{|c|}{ Panel d. Amount per resident: Contracts, grants, loans ${ }^{\mathrm{e}}$} \\
\hline With controls ${ }^{\mathrm{d}}$ & -88.73 & $-57.58 * *$ & $-88.80 *$ \\
\hline (no capitals) & $(56.59)$ & $(25.96)$ & $(46.75)$ \\
\hline$R^{2}$ & 0.379 & 0.284 & 0.284 \\
\hline No. of observations & 37 & 37 & 37 \\
\hline
\end{tabular}

a. The dependent variable is stimulus amount per state resident, using the agency-reported data from recovery.gov for panels (a) and (b) contracts, grants, and loans data for panels (c) and (d). Each cell reports the coefficient from a separate regression. Robust standard errors in parentheses. Statistical significance at the $* 10$ percent, $* * 5$ percent, and $* * * 1$ percent level.

b. The change in unemployment is the difference between the unemployment rates in January 2009 and January 2007.

c. State employment refers to the total employment in the state divided by state population, multiplied by 100 .

d. "Controls" include medicaid expenditures per capita, interstate highway miles, the poverty rate, employment per state resident, and the average of the two-party Democratic vote share in the prior election for each of the two senators.

e. Panel (d) omits the funds allocated to state capital districts.

In contrast to the district-level findings, employment ${ }^{18}$ and poverty come in negative and statistically significant in most specifications. One exception is that state employment has a positive sign and is significant at the 10 percent level in the agency data specification without controls. The employment numbers are small. Increasing the workforce in a state

18. In contrast to the district level, where we include employment, here we include the employment-to-population ratio in the state. Whereas population does not vary substantially across congressional districts, it does vary across states and we account for that by dividing employment by state population. 
by 10 percent of a state's population is correlated with a reduction in funding equal to slightly less than $\$ 9$ per person in our specification with the largest coefficient. The coefficients on poverty are sizable, negative, and statistically significant in all four specifications. Although poor areas and high employment areas were targeted within states through money set aside for poor areas and centers of employment, states with higher poverty rates and states with higher employment did not receive more money. Echoing Inman (2010), we find that the single most important explanatory variable in adding to the explained share of total variation is precrisis Medicaid expenditures per capita, which was explicitly incorporated into a Medicaid funding formula.

\section{III.C. Group Targeting: Partisanship}

We next investigate whether members of Congress acted in the interests of their parties. At the time ARRA was passed, Democrats held a strong majority in both the House and the Senate and they also held the presidency. Therefore, they were able to pass the legislation without any support from Republicans in the House. They also passed the bill in the Senate, overcoming a potential Republican filibuster, with the help of only three Republicans. Did the Democrats therefore capture a large majority of the funds for their own districts, as might be expected from simple and standard political economy models?

As Veronique De Rugy (2010) has shown, districts represented by Democrats received substantially larger sums of ARRA money than those represented by Republicans. In our database of contracts, grants, and loans, districts represented by Democrats received 55 percent more than those represented by Republicans. In table 4, we display the results from regressing the district-level amount on a dummy for Democratic member of the House. From column 1, we can see that the mean amount per person received in Republican districts was $\$ 684$, whereas in Democratic districts it was $\$ 1,057$. However, as we pointed out earlier, state capitals received funds that, while nominally allocated to the capital, were in turn allocated across the state. ${ }^{19}$ Education funds were generally allocated in this manner. The top 17 recipient districts are all part of state capitals, and 26 of the top 30 are state capital districts as well. The probability of either of these events occurring by chance is below 1 in $10^{13}$ (10 to the 13th power).

19. In addition to Silver (2010), who discusses the state capitals problem, Albouy (2009) also refers to the problem as part of his justification for running state-level regressions. 


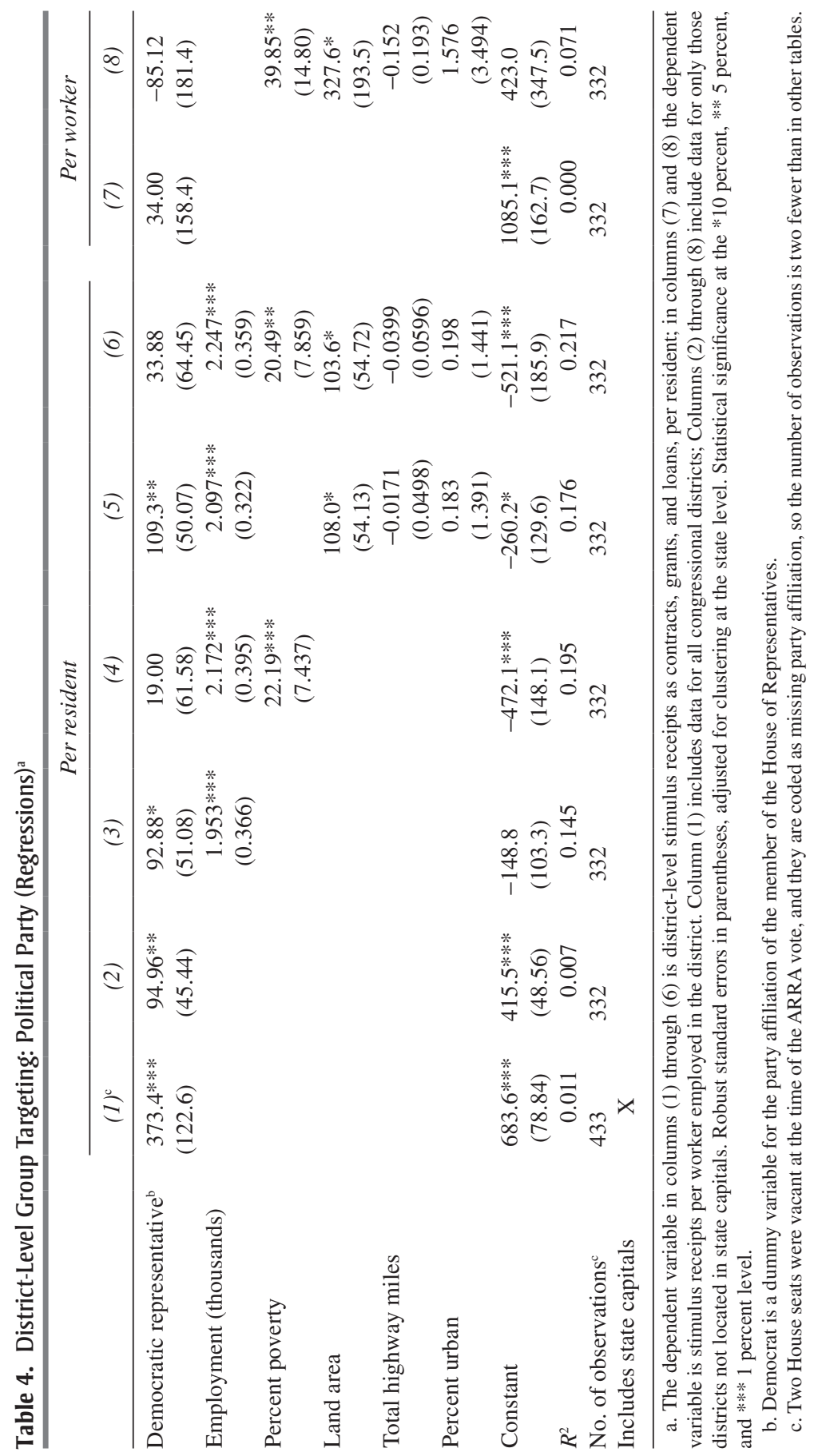


However, the pattern of funds allocations is slightly more nuanced than in Nate Silver's (2010) account. Silver argues that state capitals tend to be heavily Democratic and therefore that these transfers to state agencies are more likely to be counted as going to Democratic districts. In fact, state capital districts have almost the same Democratic vote share on average as districts not located in state capitals. In table 1, we show that the Democratic vote share for the House seat is 58 percent whether or not we include the 101 districts that contain portions of a state capital. ${ }^{20}$ While urban areas tend to vote more Democratic than others, there are many districts containing portions of state capitals and the surrounding suburban land or even surrounding rural land. For example, the entire state of Wyoming is one district. Republican districts containing state capitals are slightly larger and less dense than Democratic ones. More importantly, state capital districts in larger states do tend to be more Democratic than average, while capital districts in smaller states tend to be more Republican. The state capitals in the largest states received disproportionately larger sums because most of the education and Medicaid spending for the entire state is given to the capital, and states with large populations received more total education and Medicaid funds. The districts of the top 10 recipients are, in descending order, the capitals of California, New York, Illinois, Florida, Texas, Ohio, Michigan, Georgia, Pennsylvania, and Massachusetts. Only two of the top 17 districts, and four of the top 26 districts, were represented by a Republican member of the House of Representatives.

As explained earlier, since we do not know how the funds nominally allocated to state capitals were actually disbursed within the states, we exclude all districts that include state capitals from our district-level analysis. This also eliminates from our sample 13 states that do not have a congressional district without some part of a state capital. In our revised sample, the partisan gap is substantially lower, with Democratic districts receiving 23 percent more than Republican districts. The average Republican district receives $\$ 416$ per capita as compared to $\$ 510$ per capita in the average Democratic district; this $\$ 95$ differential is statistically significant (see column 2 of table 4). However, once we introduce the percent living in poverty as a control, the differential shrinks to a statistically insignificant $\$ 19$.

We then add additional controls. None of the controls changes the coefficient on the Democrat dummy by much, with the exception of the

20. Our set of capital districts differs slightly from Silver's. We identify 101 congressional districts containing some portion of a state capital city or its surrounding county. Silver defines 78 districts as containing all or part of a state's capital city. 
poverty variable. Column 5 of table 4 shows that, conditional on the four other funding formula controls, including employment but excluding poverty, the coefficient rises slightly to $\$ 109$ and remains significant at a 5 percent level. However, reintroducing poverty reduces the coefficient back to $\$ 33$ and makes it insignificant at conventional levels. In the perworker regressions, reported in columns 7 and 8 , the Democrat dummy is insignificant and small with or without controls. In fact, conditional upon controls, the coefficient on the Democrat dummy is $-\$ 85$. Ultimately, it is not clear whether Democrats funneled money to their districts through funding formulas that targeted high poverty areas and high employment areas or whether these areas received more because politicians were trying to create jobs in poor areas and centers of employment. Nonetheless, it seems unlikely that poor areas benefited from explicit targeting of Democratic areas. In fact, the poverty variable is slightly more strongly correlated with funds per resident in Republican areas than in Democratic ones.

We now look more closely at the amount received by congressional districts as a function of the House two-party Democratic vote share, as illustrated in the four panels of figure 3. The upper-left panel plots the CGL funds per resident against the Democratic vote share. Five Republican outliers who received substantially larger amounts stand out, and roughly triple the number of Democrats also stand out. The lower-left panel shows that the Democratic outliers are all in districts that are 100 percent or very close to 100 percent urban. Thus, it is not surprising that in the upper-right panel we see only two Democratic outliers, although we still see the same five Republican outliers. In the lower-right panel we display the results of a nonparametric regression of the worker-per-resident ratio on vote share. Interestingly, we find a similar hump for districts with 80 to 90 percent Democratic vote share. This suggests that much of the hump in funding for Democrats in the 80 to 90 percent range is attributable to those districts being centers of employment.

In the scatter plots in figure 3, we can see that Democrats receiving between 80 and 90 percent of the vote share seem to have received a higher amount of funds per capita. To assess this further, we non-parametrically regress the per capita amount of CGL funds on the Democratic Party vote share and show the results in the upper panel of figure $4 .{ }^{21} \mathrm{We}$ also use a semiparametric partial linear model to regress the per capita CGL funds on the

21. We use the Stata command lpoly, using a "rule of thumb" plug-in bandwidth that minimizes the conditional weighted-mean integrated square error. Standard errors are obtained by bootstrapping with 100 replications. 
Figure 3. District-Level Stimulus Amount per Resident and Amount per Worker

Stimulus amount per resident ${ }^{\mathrm{a}}$ vs. vote share ${ }^{\mathrm{b}}$

Dollars per resident

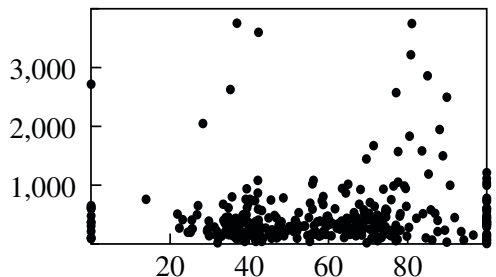

Democratic vote share (percent)

\section{Stimulus amount per resident $\mathrm{t}^{\mathrm{a}}$} vs. percent urban ${ }^{\mathrm{b}}$

Dollars per resident

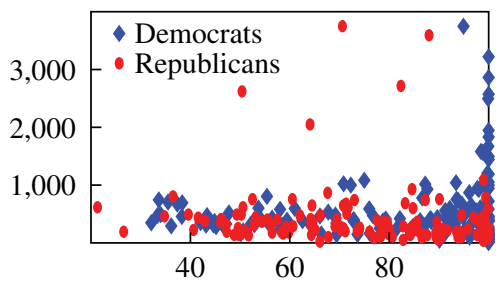

Percent urban (percent)
Stimulus amount per worker vs. vote share ${ }^{\text {b }}$

Dollars per worker

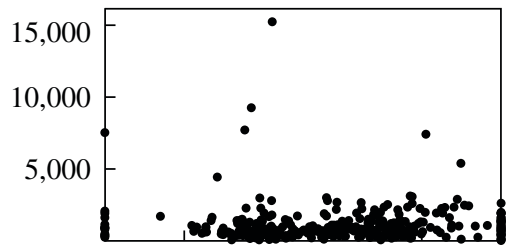

20

$60 \quad 80$
Democratic vote share (percent)

\section{Worker-to-resident ratio and vote share ${ }^{\mathrm{d}}$}

Ratio of workers to residents

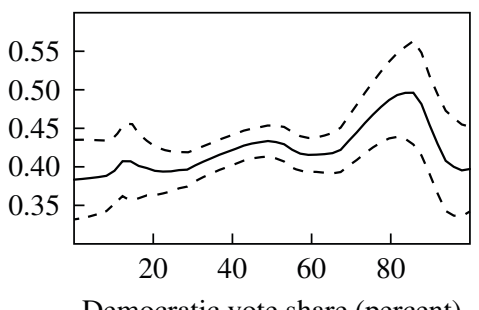

Source: Authors' calculations.

a. "Amount per resident" refers to people living in the congressional district.

b. For the scatter plots, each dot represents one of the 334 districts not containing state capitals.

c. "Amount per worker" refers to all people employed within the congressional district, though they may reside elsewhere.

d. Panel displays the results of a non-parametric regression of the worker-to-resident ratio on the Democratic vote share.

Democratic Party vote share, controlling parametrically for our five funding formula controls: percent living in poverty, percent living in an urban area, land area, road miles, and employment (lower panel). We estimate:22

$$
A_{i}=f\left(v_{i}\right)+X \beta+\varepsilon_{t},
$$

22. Due to concerns that very urban districts got substantially more money and are also highly Democratic, we ran specifications controlling for a dummy variable that takes on a value of one for districts with 100 percent of their area in urban land. We also tried controlling for a dummy that takes on a value of one if a district has 90 percent or more of its land in urban areas. Our results are highly robust to these alternative specifications. 
Figure 4. District-Level Non-parametric and Semi-parametric Regressions of Stimulus Amount per Resident on Democratic Vote Share

\section{Non-parametric ${ }^{\mathrm{a}}$}

Dollars per resident

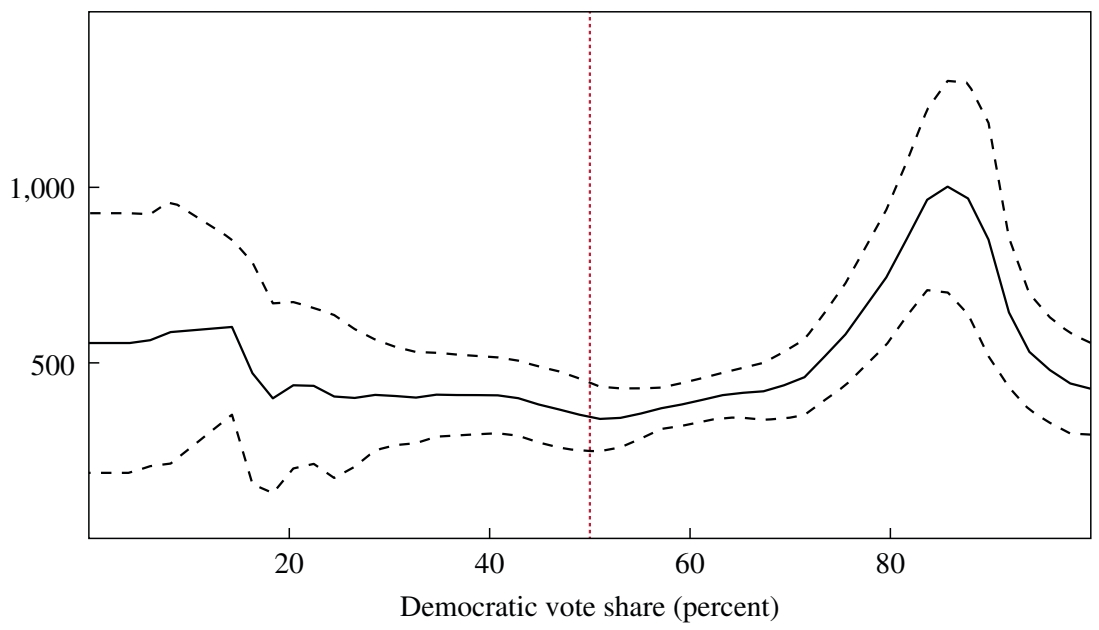

\section{Semi-parametric ${ }^{b}$}

Dollars per resident

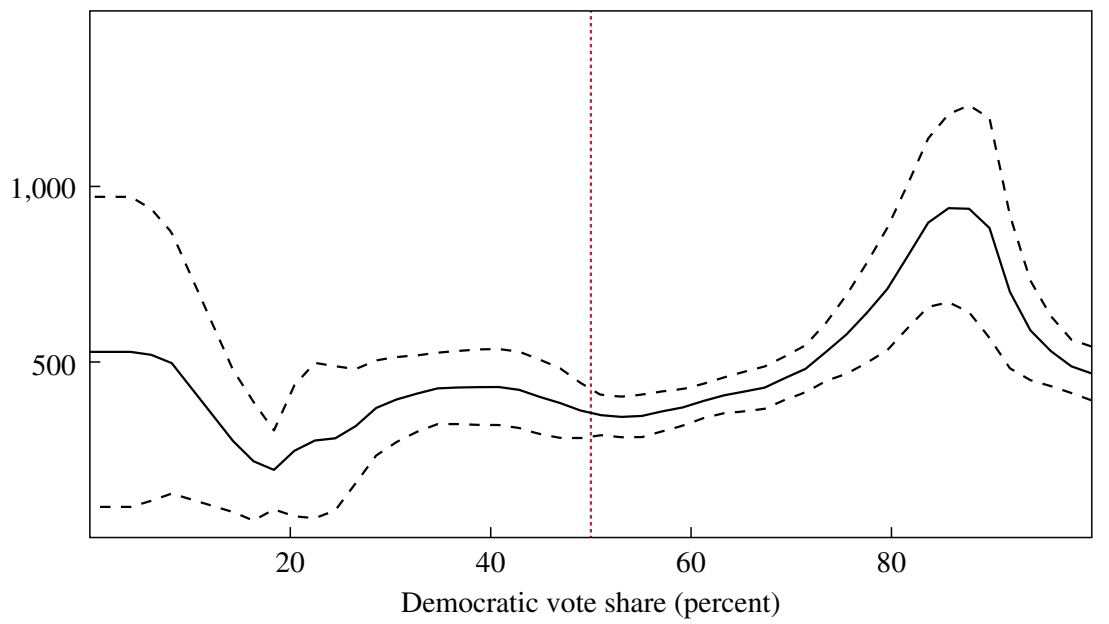

Source: Authors' calculations.

a. Results of a non-parametric regression (using kernel-weighted local polynomial smoothing) of stimulus amount per resident on Democratic vote share.

b. Results of a semi-parametric regression that includes (parametric) controls for employment, poverty rate, percent urban, land area, and road miles. Sample includes 334 congressional districts not located in state capitals. 
where $A_{i}$ is the per capita amount of ARRA funding received in district $i$, $X$ is the set of demographic and economic controls, and $f\left(v_{i}\right)$ is a nonparametric function of the two-party Democratic vote share. ${ }^{23}$ The results are shown in the right-hand panel of figure 4.

The upper panel of figure 4 confirms the evidence found in the simple scatter plot showing that strongly Democratic districts with around 80 percent of the vote share receive well above the mean amount of CGL funds. The lower panel of figure 4 shows that this relationship continues to hold after we account for covariates. The upper panel also suggests that highly Republican districts get a modest amount more than the average recipient, although this difference is not statistically significant and does not survive the inclusion of covariates as shown in the lower panel.

Figure 5 shows the same results, with amount per worker as the lefthand side variable. In the upper panel of figure 5, we see that whereas Democrats in the 80 to 90 percent vote share range do not get as much more as in the per-resident figure, they still do get more than Democrats in less safe districts. However, highly Republican districts also now get substantial amounts. The bootstrapped confidence intervals are much wider for the very Republican districts, because they are driven by one outlier that received a substantial amount. Putting in our five controls also increases the amount received per capita for marginal Republican districts, though not for marginal Democratic ones.

Interestingly, in table 5, when we compare closely elected Democrats to closely elected Republicans, we find that their districts receive about the same amount. If anything, the marginal Democratic districts obtained less in CGL funds, since the coefficient on the difference between marginal Democrats and the reference group of marginal Republicans is negative in four out of five specifications. However, it is never statistically significant. Democratic and Republican districts with around 50 percent Democratic vote share are likely to be similar in terms of other characteristics, so comparing these districts offers another way to test whether the partisan representation of the district affects the spending allocation.

23. We use the Yatchew method to difference out the parametric component $X$, and use local polynomial regression (Stata command lpoly) to estimate the $f\left(v_{i}\right)$ component nonparametrically; the bandwidth selection is based on the "rule of thumb" plug-in method. Standard errors are obtained by bootstrapping with 100 replications. 
Figure 5. District-Level Non-parametric and Semi-parametric Regressions of Stimulus Amount per Worker on Democratic Vote Share ${ }^{a}$

\section{Non-parametric}

Dollars per worker

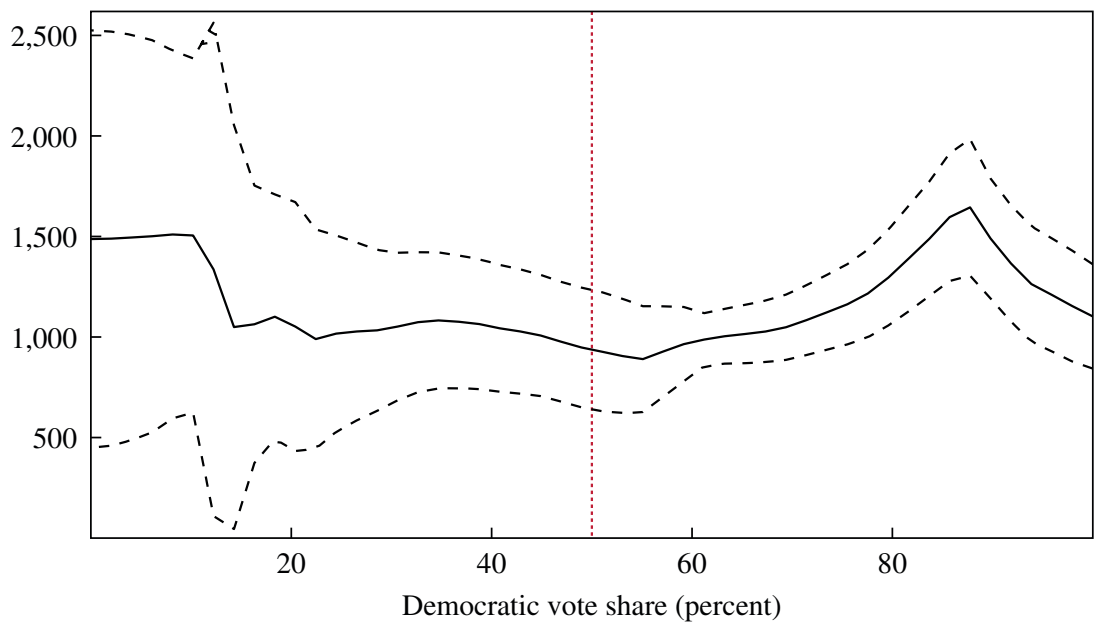

\section{Semi-parametric}

Dollars per worker

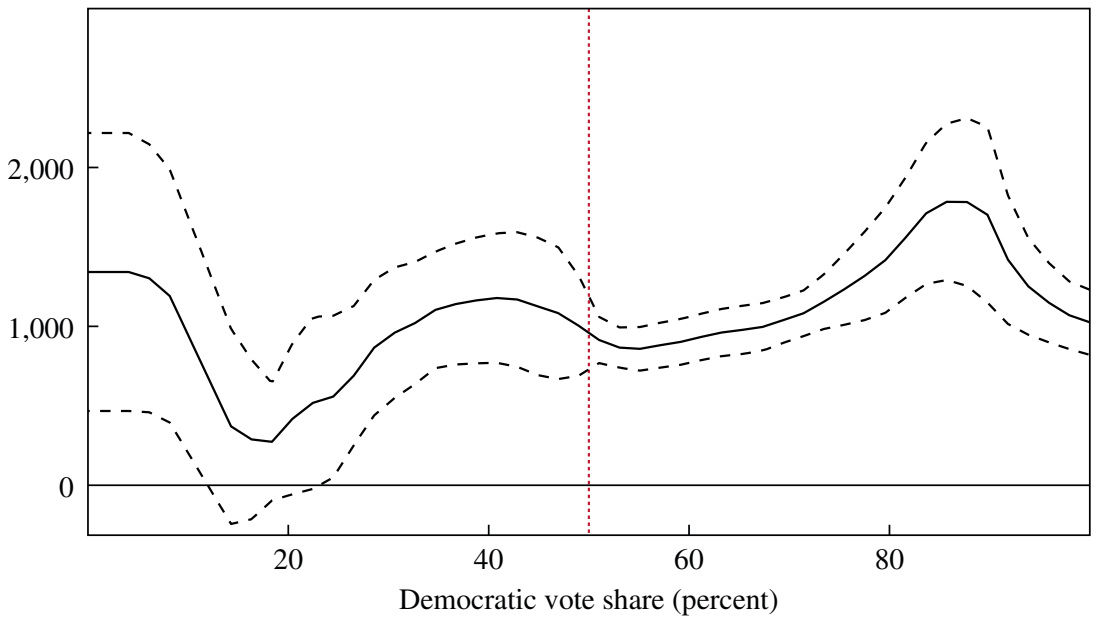

Source: Authors' calculations.

a. Regression methods correspond to those described under figure 4, except that the dependent variable in these panels is amount per worker, and in the lower panel employment is not included in the set of controls. 
Table 5. District-Level Group Targeting: Vote Share Blocks (Regressions) ${ }^{\mathrm{a}}$

\begin{tabular}{|c|c|c|c|c|c|}
\hline \multirow{2}{*}{$\begin{array}{l}\text { Vote share block (and } \\
\text { other variables) }\end{array}$} & \multicolumn{3}{|c|}{ Per resident } & \multicolumn{2}{|c|}{ Per worker } \\
\hline & (1) & (2) & (3) & (4) & (5) \\
\hline $\begin{array}{l}\text { Unopposed } \\
\text { Republican (13) }\end{array}$ & $\begin{array}{c}161.5 \\
(130.9)\end{array}$ & $\begin{array}{l}242.1 * * \\
(115.7)\end{array}$ & $\begin{array}{c}123.8 \\
(106.5)\end{array}$ & $\begin{array}{c}437.9 \\
(278.7)\end{array}$ & $\begin{array}{c}150.7 \\
(290.3)\end{array}$ \\
\hline $\begin{array}{l}\text { Democratic vote share } \\
1-30 \text { percent }(16)\end{array}$ & $\begin{array}{r}70.13 \\
(133.8)\end{array}$ & $\begin{array}{l}147.9 \\
(124.8)\end{array}$ & $\begin{array}{l}-95.42 \\
(174.0)\end{array}$ & $\begin{array}{r}77.35 \\
(343.1)\end{array}$ & $\begin{array}{l}-579.6 \\
(537.4)\end{array}$ \\
\hline $\begin{array}{l}\text { Democratic vote share } \\
30-40 \text { percent }(63)\end{array}$ & $\begin{array}{l}-6.304 \\
(100.3)\end{array}$ & $\begin{array}{r}60.67 \\
(105.8)\end{array}$ & $\begin{array}{c}26.38 \\
(91.28)\end{array}$ & $\begin{array}{l}-31.88 \\
(321.4)\end{array}$ & $\begin{array}{l}-117.2 \\
(287.7)\end{array}$ \\
\hline $\begin{array}{l}\text { Democratic vote share } \\
50-60 \text { percent }(42)\end{array}$ & $\begin{array}{c}-32.82 \\
(66.14)\end{array}$ & $\begin{array}{c}13.01 \\
(89.64)\end{array}$ & $\begin{array}{l}-56.16 \\
(87.81)\end{array}$ & $\begin{array}{l}-138.5 \\
(285.7)\end{array}$ & $\begin{array}{l}-330.1 \\
(298.4)\end{array}$ \\
\hline $\begin{array}{l}\text { Democratic vote share } \\
60-70 \text { percent }(44)\end{array}$ & $\begin{array}{c}12.87 \\
(67.85)\end{array}$ & $\begin{array}{c}86.87 \\
(75.33)\end{array}$ & $\begin{array}{l}15.65 \\
(71.92)\end{array}$ & $\begin{array}{l}-39.66 \\
(263.1)\end{array}$ & $\begin{array}{l}-228.8 \\
(254.6)\end{array}$ \\
\hline $\begin{array}{l}\text { Democratic vote share } \\
70-80 \text { percent }(51)\end{array}$ & $\begin{array}{l}105.4 * * \\
(40.03)\end{array}$ & $\begin{array}{l}146.4 * * * \\
(47.52)\end{array}$ & $\begin{array}{l}100.1 \\
(64.82)\end{array}$ & $\begin{array}{r}34.42 \\
(219.4)\end{array}$ & $\begin{array}{l}-101.7 \\
(235.6)\end{array}$ \\
\hline $\begin{array}{l}\text { Democratic vote share } \\
80-90 \text { percent }(20)\end{array}$ & $\begin{array}{l}792.9^{* * *} \\
(144.0)\end{array}$ & $\begin{array}{l}685.3^{* * *} \\
(147.3)\end{array}$ & $\begin{array}{l}603.7 * * * \\
(189.1)\end{array}$ & $\begin{array}{l}837.3^{* *} \\
(390.6)\end{array}$ & $\begin{array}{c}658.6 \\
(460.0)\end{array}$ \\
\hline $\begin{array}{l}\text { Democratic vote share } \\
90-99 \text { percent }(5)\end{array}$ & $\begin{array}{l}-21.47 \\
(188.0)\end{array}$ & $\begin{array}{r}261.3^{*} \\
(135.5)\end{array}$ & $\begin{array}{l}106.6 \\
(206.7)\end{array}$ & $\begin{array}{l}405.7 \\
(395.0)\end{array}$ & $\begin{array}{l}-100.5 \\
(551.4)\end{array}$ \\
\hline $\begin{array}{l}\text { Unopposed } \\
\text { Democrat (34) }\end{array}$ & $\begin{array}{r}47.45 \\
(103.5)\end{array}$ & $\begin{array}{l}125.2 \\
(115.0)\end{array}$ & $\begin{array}{r}51.49 \\
(139.3)\end{array}$ & $\begin{array}{l}-16.47 \\
(353.5)\end{array}$ & $\begin{array}{l}-215.5 \\
(374.0)\end{array}$ \\
\hline $\begin{array}{l}\text { Employment } \\
\text { (thousands) }\end{array}$ & & $\begin{array}{l}1.741 * * * \\
(0.334)\end{array}$ & $\begin{array}{l}2.019 * * * \\
(0.315)\end{array}$ & & \\
\hline$R^{2}$ & 0.121 & 0.220 & 0.277 & 0.031 & 0.101 \\
\hline $\begin{array}{l}\text { No. of observations } \\
\text { Additional controls } \mathrm{s}^{\mathrm{c}}\end{array}$ & 334 & 334 & 334 & 334 & $\begin{array}{r}334 \\
\times\end{array}$ \\
\hline
\end{tabular}

a. The dependent variable in columns (1) to (3) is stimulus receipts per district resident; the dependent variable in columns (4) and (5) is stimulus receipts per worker (that is, per person employed in the district). Robust standard errors in parentheses, adjusted for clustering at the state level. Statistical significance indicated at the $* 10$ percent, $* * 5$ percent, and $* * * 1$ percent level.

b. The vote share blocks are dummy variables that equal 1 if the Democratic vote share for that representative falls in the specified range. The number of representatives in each group is indicated in parentheses. The omitted category is $40 \%-50 \%$ Democratic vote share; there are 46 representatives in this group. c. "Additional controls" include poverty rate, percent urban, land area, and road miles.

By contrast, the point estimates for Democratic districts with between 80 and 90 percent vote share are large in all specifications and statistically significant at a 5 percent or lower level in four out of five specifications. The effects in per-worker terms are smaller in magnitude, even after adjusting for the fact that there are two to three residents per worker in an average district. This is consistent with the number of Democratic outliers being much smaller in per-worker terms than in per-resident terms. These results lend support to the argument that the higher average level of spending in Democratic districts is driven more by district characteristics than by party affiliation per se. However, the fact that a substantially larger amount of 
CGL funds went to districts where Democrats received between 80 and 90 percent of the vote share suggests that there may be a partisan gap in funds, or some other factor that may be different in these districts.

At the state level, in table 6 we look at the correlation between ARRA receipts and the party of the state's governor, a dummy variable for states that supported Obama by a 2-percentage-point vote margin or less, a variable with the number of Democratic senators in the state, and the Democratic vote share in the previous Senate elections averaged over both senators in each state. We find no evidence that Democratic governors received a greater amount of funds, ${ }^{24}$ nor do we find evidence that swing states-those that marginally supported Obama in the 2008 electionbenefited. If anything, swing states (Florida, Indiana, and North Carolina) received less than other states; in two of our four state-level specifications, the coefficients are statistically significant at a 5 percent level and of moderate to large size. The results are not robust, because the coefficient size is much smaller when controlling for funding formula covariates and when we include the money reported as accruing to state capitals. Regardless, swing state supporters of the president certainly did not benefit in ARRA.

Our partisanship results for the Senate are similar to our district-level results for the House, in the sense that highly Democratic areas receive slightly more funds on average. Using the agency data, the coefficient on the number of Democratic senators is $\$ 186$ per resident without controls and $\$ 130$ per resident with controls. The estimated coefficient is roughly half the size using the CGL data on the full sample of states (table 6, third row), and it is virtually zero after stripping out the state capitals (fourth row). We find a similar pattern of results when considering the average Democratic vote share of the two senators. The unconditional correlation in table 6 (first row) suggests that a 10 percent increase in the Democratic vote share of both senators increases ARRA funding by about $\$ 100$ per capita. (Recall that the average level of funding in the agency-reported data is about $\$ 1,600$ per capita.) The difference between the agency data results and the CGL results partially reflects the fact that agency data contain 60 percent more of the ARRA bill expenditures than the CGL data do. However, the difference also reflects the fact that states with more generous welfare programs received more funds, and these states tend to be

24. Democratic governorship at the time of passage of ARRA has been used as an instrument for stimulus (Conley and Dupor 2013). However, we find that the Democratic governorship dummy has a low marginal $R^{2}$, is not statistically significant, and oscillates in sign depending upon covariates. 
Table 6. State-Level Group Targeting: Partisanship (Regressions) ${ }^{\mathrm{a}}$

\begin{tabular}{|c|c|c|c|c|}
\hline & $\begin{array}{l}\text { Democratic } \\
\text { governor }\end{array}$ & $\begin{array}{c}\text { Obama } \\
\text { 50-52 percent }\end{array}$ & $\begin{array}{c}\text { No. of } \\
\text { Democratic } \\
\text { senators }^{\mathrm{c}}\end{array}$ & $\begin{array}{c}\text { Senate } \\
\text { Democratic } \\
\text { vote share }^{\mathrm{d}}\end{array}$ \\
\hline \multicolumn{5}{|c|}{ Panel a. Amount per resident: Agency-reported } \\
\hline No controls & $\begin{array}{r}43.78 \\
(120.7)\end{array}$ & $\begin{array}{c}-239.2 * * * \\
(76.71)\end{array}$ & $\begin{array}{l}185.8 * * * \\
(62.13)\end{array}$ & $\begin{array}{l}10.41 * * * \\
(3.739)\end{array}$ \\
\hline$R^{2}$ & 0.003 & 0.018 & 0.136 & 0.115 \\
\hline No. of observations & 50 & 50 & 49 & 50 \\
\hline \multicolumn{5}{|c|}{ Panel b. Amount per resident: Agency-reported } \\
\hline With controls ${ }^{\mathrm{e}}$ & $\begin{array}{r}14.86 \\
(103.0)\end{array}$ & $\begin{array}{r}-101.1 \\
(84.47)\end{array}$ & $\begin{array}{l}129.9 * * * \\
(43.97)\end{array}$ & $\begin{array}{l}8.765^{* * *} \\
(2.966)\end{array}$ \\
\hline$R^{2}$ & 0.367 & 0.370 & 0.424 & 0.436 \\
\hline No. of observations & 50 & 50 & 49 & 50 \\
\hline \multicolumn{5}{|c|}{ Panel c. Amount per resident: Contracts, grants, loans } \\
\hline With controls ${ }^{e}$ & $\begin{array}{l}-134.9 \\
(82.55)\end{array}$ & $\begin{array}{r}-175.5^{*} \\
(89.56)\end{array}$ & $\begin{array}{c}69.82 \\
(47.63)\end{array}$ & $\begin{array}{l}6.902 * * \\
(3.157)\end{array}$ \\
\hline$R^{2}$ & 0.664 & 0.651 & 0.655 & 0.681 \\
\hline No. of observations & 50 & 50 & 49 & 50 \\
\hline \multicolumn{5}{|c|}{ Panel d. Amount per resident: Contracts, grants, loans } \\
\hline $\begin{array}{l}\text { With controls } \\
\text { (no state capitals) }\end{array}$ & $\begin{array}{c}96.18 \\
(70.38)\end{array}$ & $\begin{array}{c}-233.2 * * * \\
(80.80)\end{array}$ & $\begin{array}{r}0.253 \\
(49.94)\end{array}$ & $\begin{array}{l}-0.232 \\
(2.857)\end{array}$ \\
\hline$R^{2}$ & 0.312 & 0.340 & 0.281 & 0.284 \\
\hline No. of observations & 37 & 37 & 36 & 37 \\
\hline
\end{tabular}

a. The dependent variable is stimulus amount per state resident, using the agency-reported data from recovery.gov for panels (a) and (b), and the contracts, grants, and loans data for panels (c) and (d). Panel (d) omits the funds allocated to state capital districts. Each cell reports the coefficient from a separate regression. Robust standard errors in parentheses. Statistical significance indicated at the $* 10$ percent, **5 percent, and ***1 percent level.

b. A dummy variable indicating whether 2008 presidential vote share fell in that range.

c. Number of Democratic or independent senators for a given state (a value of 0,1 , or 2); Minnesota is omitted from the specification since one Senate seat was vacant at the time.

d. Average of the two-party Democratic vote share in the prior election for each of the two senators.

e. "Controls" include Medicaid expenditures per capita, interstate highway miles, the poverty rate, and employment per state resident.

more Democratic. ${ }^{25}$ The fact that the Senate relied on Republicans in the ARRA vote, whereas the House did not, does not seem to have affected the degree to which Democratic districts benefited relative to Democratic states. Finally, we show in online appendix figure A6 a plot of the statelevel amount per resident on presidential vote share, using both the agency

25. Recall that unemployment insurance and Medicaid funds are included in the agencyreported data but not in the CGL data. 
data and the CGL data. There is a clear positive relationship in the agency data but no relationship in the CGL data.

Overall, we find that Democratic districts did get a modest amount more per resident than Republican districts. However, much of the differential is attributable to differential poverty rates and employment concentrations in Democratic areas at the district level and to differences in the generosity of welfare programs at the state level. It is not clear whether Democratic districts and states received more on average than Republican districts because the bill targeted Democratic Party priorities, such as poverty reduction, or whether those areas received more funds because they were Democratic.

\section{III.D. Individual Targeting: Party Elites}

Did Congressional legislators use their individual positions of power to their own benefit? We break down per capita ARRA funds by whether state and district representatives and senators had leadership positions in Congress, whether they were legislative swing voters, and how long they had been members in Congress. Our findings are predominantly negative; that is, powerful politicians don't appear to have received more funds.

The Democratic leadership in the House, including committee chairs and party leaders, did not receive more CGL funds for their districts than average. Out of twenty Democratic leaders in our sample, only two were in the top 10 percent of recipient districts. The top recipient in the Democratic Party leadership was the Speaker of the House, Nancy Pelosi. Her district, in San Francisco, received the 11th largest amount of funds of the 334 representatives in our sample. The second largest recipient amount within the Democratic leadership went to Patrick Murphy's district in Pennsylvania, which includes Levittown and surrounding areas; it received the 28th highest amount overall.

In table 7, we regress amount per resident and per worker on dummies for the Democratic leadership and for the Republican leadership separately. For Republican leaders, in addition to the party leadership, we include the ranking members of committees. We do this both with and without our baseline controls. We show that Democratic congressional leaders on average received the same or lower amounts than other members of Congress. The coefficient on the Democratic leadership is not statistically significant in any of the specifications; it is zero in the per-resident specification without controls and negative in all others.

In online appendix table A4, we report the dummies, separating out the Speaker of the House (Nancy Pelosi) on the Democratic side and the Minority Leader (John Boehner) on the Republican side. Pelosi is an 


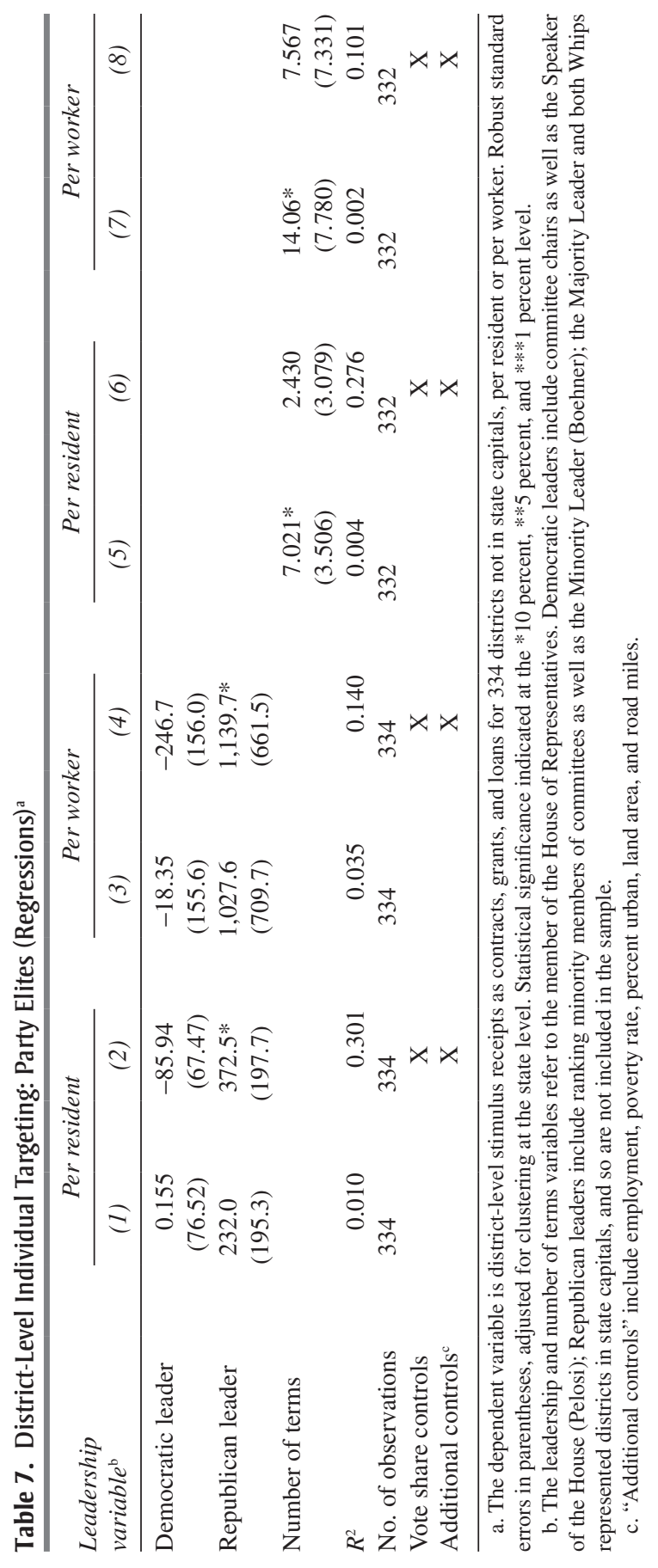


outlier, and the speaker dummy is statistically significant at the 1 percent level in all specifications except the per-worker specification with controls. In the per-resident specification with controls, Pelosi received almost $\$ 600$ more per resident than other similar members. Conditional on the speaker dummy, the rest of the Democratic leadership received significantly (at the 5 percent level) less when the regression controls for funding formula amounts, in both the per-worker and the per-resident (\$125 less) specifications. On the other hand, returning to table 7, we see that in all specifications, the Republican leadership received more than average. With controls, the amounts are statistically significant at the 10 percent level. However, the minority leader on the Republican side is also an outlier. His district received \$335 less per resident, unconditionally, and \$151 less conditional upon controls. Although Boehner's district ranked in the 11th percentile in overall fund distribution, the Boehner results are significant at the 1 percent level without controls, suggesting that these estimates are plagued by small sample sizes and skewed data. After accounting for Boehner, the rest of the Republican leadership gets $\$ 409$ more on average, conditional upon controls, and this is significant at the 10 percent level. Again however we note that these results are driven by two outliers: Representative Buck McKeon and Representative Doc Hastings, whose districts received \$3,319 more per resident, on average. Taking out these two outliers, we do not find evidence that the rest of the Republican leadership received more than other congressional members (see online appendix table A4).

Because of the small numbers of party leaders and the skewness of the distribution of funding, we also carry out small sample tests to assess whether these individuals received a disproportionate amount of CGL funds. Intuitively, by comparing those seated when the ARRA bill was passed (the 111th Congress) to those seated in both the following and prior sessions of Congress, we can estimate the impact of being in power precisely when the ARRA bill passed. We match the districts of current congressional leaders in the 111th Congress to the districts of their predecessors who held the same positions in the 110th Congress. There were six Republican leaders whom we could match, due to a number of exits of Republicans in the leadership of the 110th Congress. In five out of those six cases, the district with a leader in power during the ARRA vote received more money. This would happen by random chance only 4 percent of the time (using a one-sided test). We also look at leadership changes between the 111th and 112th Congress. For Republicans, this raises our sample size to 10 . We find that in seven out of those 10 cases, the district with a leader in power during the ARRA vote received more, which would 
happen by random chance with a probability of 8.9 percent. We run the same comparison for Democratic leaders as well. In the case of Democrats, there is no evidence that committee chairs received more money; in only five out of 11 cases did the leader in power during the ARRA vote get more. These results are reported in online appendix table A5.

It is more difficult to analyze the impact of committee chair positions in the Senate. Thirty-two states have senators who were either committee chairs or ranking members at the time of the ARRA vote. When we run a state-level regression of the amount of stimulus funds on a dummy for a state with a committee chair or ranking minority member, we find the coefficient to be negative in all four of our usual specifications. These coefficients, however, are not statistically significant in any specification. We also note that Inman (2010) finds in his regressions that the states with committee chairs or ranking members on the powerful fiscal-related Senate committees received a statistically insignificantly lower amount than other states.

Overall, then, we find no evidence that states with powerful senators or House members received more ARRA funds.

Legislative tenure can be thought of as a proxy for influential social or collegial relationships with other legislators or for institutional knowledge of the functioning of Congress. For this reason, it is possible that longer-tenured legislators are able to procure a greater amount of funds. In table 7 , the third row shows that tenure is positively correlated with both the amount received per resident and the amount received per worker. Both are significant at the 10 percent level. However, the upper-right panel of figure 6 shows that many of the longer-tenured (shaded more heavily) observations are in the 80 to 90 percent range. Conditional upon baseline controls, coefficients drop by a half to two-thirds. An additional two-year congressional session is associated with $\$ 2.50$ more in funds per resident and is not statistically significant at conventional levels. We show, in online appendix figure A7, non-parametric and semi-parametric regressions of the amount received per capita on tenure, broken down as well by party. Among Republicans, we can see that very long-tenured individuals actually receive less, and among Democrats, the increases in funding with increased tenure are solely due to a few outliers, members who have more than 50 years in the House.

We show similar results in the Senate in the second column of table 9. Here the results are even starker than in the House. All of the coefficients on years in the Senate are small and none are statistically significant at conventional levels. In the third column, we show that average congressional 
Figure 6. District-Level Stimulus Amount per Resident ${ }^{\mathrm{a}}$

By percent urban ${ }^{\mathrm{b}}$

Dollars per resident

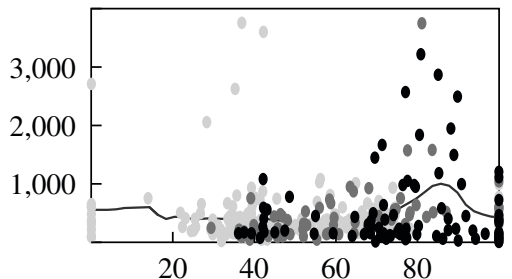

Democratic vote share (percent)

- 0\%-90\% urban

- 90\%-99\% urban

- $99 \%-100 \%$ urban

By party leadership ${ }^{\mathrm{d}}$

Dollars per resident

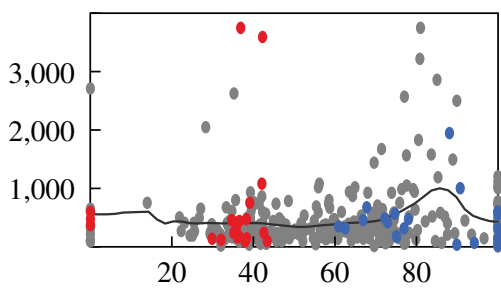

Democratic vote share (percent)

- Republican leader

- Democrat leader
By tenure ${ }^{\mathrm{c}}$

Dollars per worker

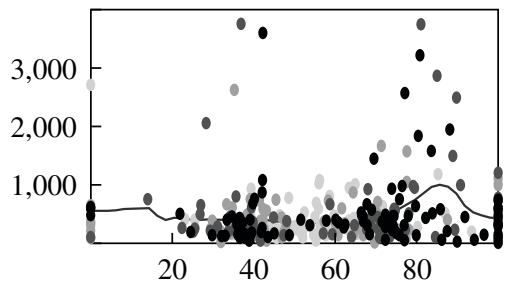

Democratic vote share (percent)

- Newest members

- Longest-tenured members

By ARRA vote

Ratio of workers to residents

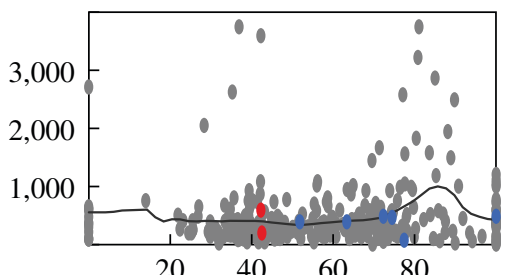

Democratic vote share (percent)

- Republican voting Yes or abstaining

- Democrat voting No or abstaining

Source: Authors' calculations.

a. Each dot represents one of the 334 districts not containing state capitals.

b. Percentage of the district population living in urban areas.

c. "Tenure" refers to the number of terms served by the congressional representative.

d. "Leadership" refers to party leaders and committee chairs (for Democrats) or ranking members (for Republicans) in the U.S. House of Representatives.

tenure ${ }^{26}$ in the state is positively correlated with the amount received when we use the agency data, likely reflecting longer tenure for states with more generous welfare programs. Conditional upon controls, the size of the coefficient drops from $\$ 15$ per resident per year of tenure to below $\$ 10$ per resident per year. In the CGL data, we find no significant correlation, and the coefficient sign turns negative with controls.

26. We define average congressional tenure to be the average number of years of tenure in the House plus the average years of tenure in the Senate, divided by two. 
Overall, we find little evidence that socially connected legislators or legislators in positions of power were able to grab more funds.

\section{III.E. Individual Targeting: Pivotal Members of Congress and Party Discipline}

Legislators can also use their individual power to gain political rents by claiming to be undecided. Since legislators in the middle of the ideological distribution can more credibly claim to be undecided and thus to need "persuading" in terms of rents for their district, we look at how the ideology of members of Congress correlates with per capita receipts of ARRA funding. We use the first dimension of McCarty, Poole, and Rosenthal's (2006) DW-Nominate, which is the most commonly used measure of congressional ideology. In the modern era, more than 85 percent of legislative voting behavior can be explained by the first dimension alone.

We are interested in how ideology correlates with funding for two reasons. First, theories of congressional politics suggest that moderate politicians may be able to capture larger amounts of rents because they are swing voters on bills and thus able to demand compensation in order to vote in favor of a bill. Second, we want to make sure that returns to vote share are not simply proxying returns to ideology. In online appendix figure A8, we semi-parametrically regress ARRA receipts per capita at the district level on DW-Nominate, controlling for baseline funding formula controls in both panels A and B but including linear vote share controls in panel B. Liberal members do receive more funds. This is also seen in the first column of table 8 . However, vote share controls reduce the estimated magnitude and take away the statistical significance of DW-Nominate. Moreover, the coefficient on DW-Nominate is small and is not statistically significant in the per-worker regressions with or without controls. In the second column of table 8, we replace DW-Nominate with its absolute value to capture ideological extremity (as opposed to partisanship). The results are very similar.

The DW-Nominate results are unsurprising, because ARRA was expected to pass with a wide margin in the House and thus no single member was pivotal. By contrast, in the Senate the administration had to negotiate to get three Republicans (Susan Collins of Maine, Olympia Snowe of Maine, and Arlen Specter of Pennsylvania) to break a potential filibuster. Moreover, one conservative Democrat, Senator Ben Nelson of Nebraska, publicly aired his ambivalence about voting in favor of the bill. In column 3 of table 8, we put in a dummy for districts located in Pennsylvania and Nebraska. Unfortunately, we cannot include the two Maine districts in our analysis because both contain part of the state capital. The coefficient 


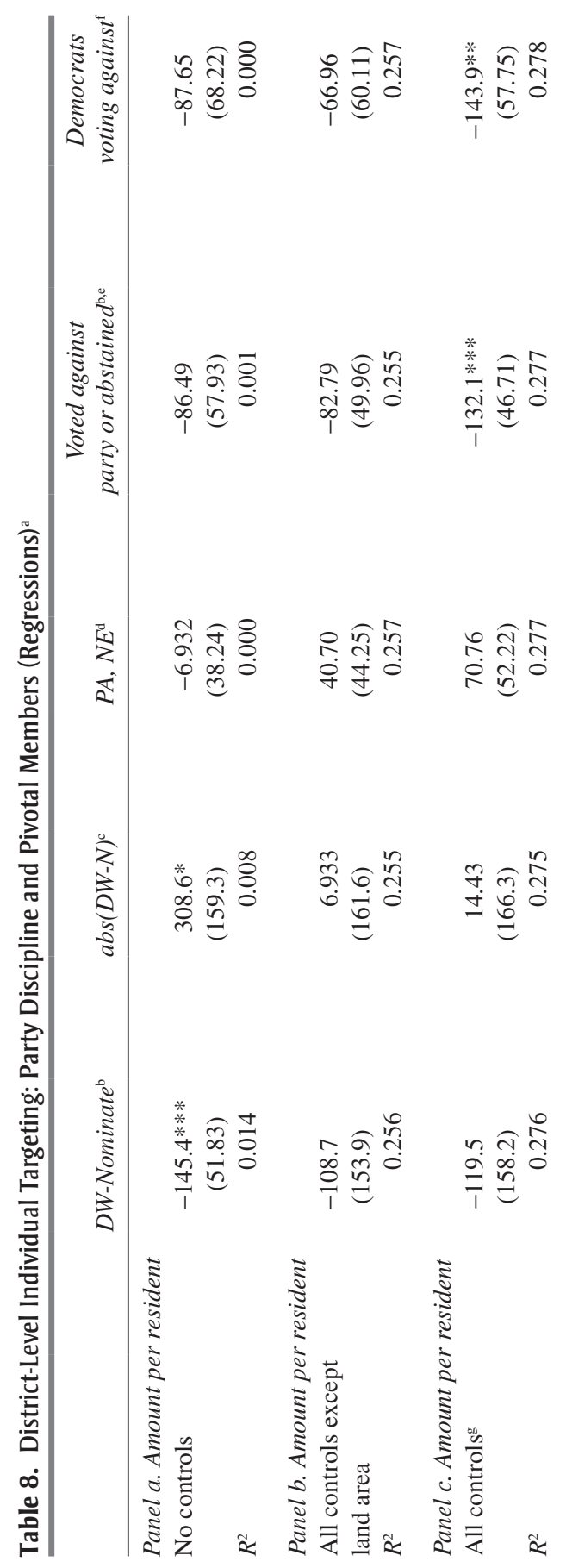




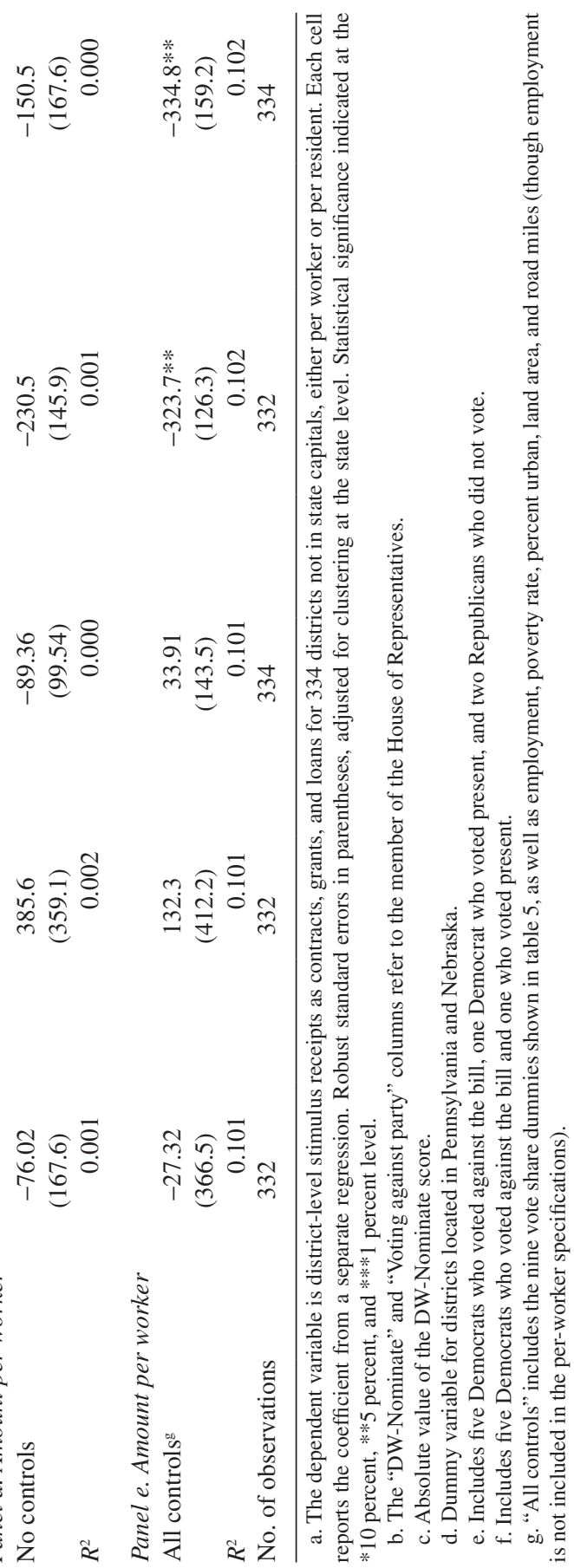


on the dummy ranges from -89 to +71 but is far from significant in all specifications.

More importantly, in our state-level analysis in table 9, the estimates are consistently negative and sometimes statistically significant. We show eight results total, four with a dummy for Maine, Pennsylvania, and Nebraska, and four with a dummy for only Pennsylvania and Nebraska. ${ }^{27}$ Estimates range from $-\$ 41$ to $-\$ 288$ across the CGL and agency data sets and two of the seven different results are significant at a 5 percent level or lower. In three out of three specifications, adding in Maine lowers the magnitude of the coefficients. However, the coefficients are negative in all specifications. We take this as strong evidence that pivotal states did not receive more money. If anything, they received less.

Another measure of whether legislators act in the interests of their party is whether they punish party members who deviate from the party line. When ARRA was passed, a few legislators voted against the majority of their own party: Republicans in the House who abstained from voting and in the Senate who even voted for it, and Democrats who abstained from voting or voted against the bill. No House Republicans voted for the bill; however, two refrained from voting. Additionally, seven Democrats voted against the bill, one voted "present," and one did not vote. Party defiers did get less on average than those voting with their parties, in both the Democratic and the Republican party. Coefficients are not significant at conventional levels and amount to $-\$ 86$ pooled across parties or $-\$ 88$ for Democrat defiers. These results are shown in the last two columns of table 8.

Putting in most baseline controls does not dramatically change the estimates. However, adding land area increases coefficient magnitudes. With the full set of baseline controls, defiers do get less and results are statistically significant in per-worker or per-resident specifications at the 5 percent level or less. For Democrats, the amounts are $-\$ 144$. However, looking at figure 6 (lower-right panel), we see that with the exception of one outlier, Democratic defiers get exactly the expected amount conditional upon vote share. Representative Dan Lipinski, a Democrat who represents the Third Congressional District in the suburbs of Chicago, was a strong outlier, and his district received only $\$ 75$ per resident. Lipinski voted "present" on the bill, and his district received the 17th lowest amount per capita in

27. Note that the results in the specification, taking out state capitals (fourth row), are identical for the regression with Maine and the one without since both Maine districts contain part of Kennebec County, which contains the state capital of Augusta. Thus both districts are not in the sample. 


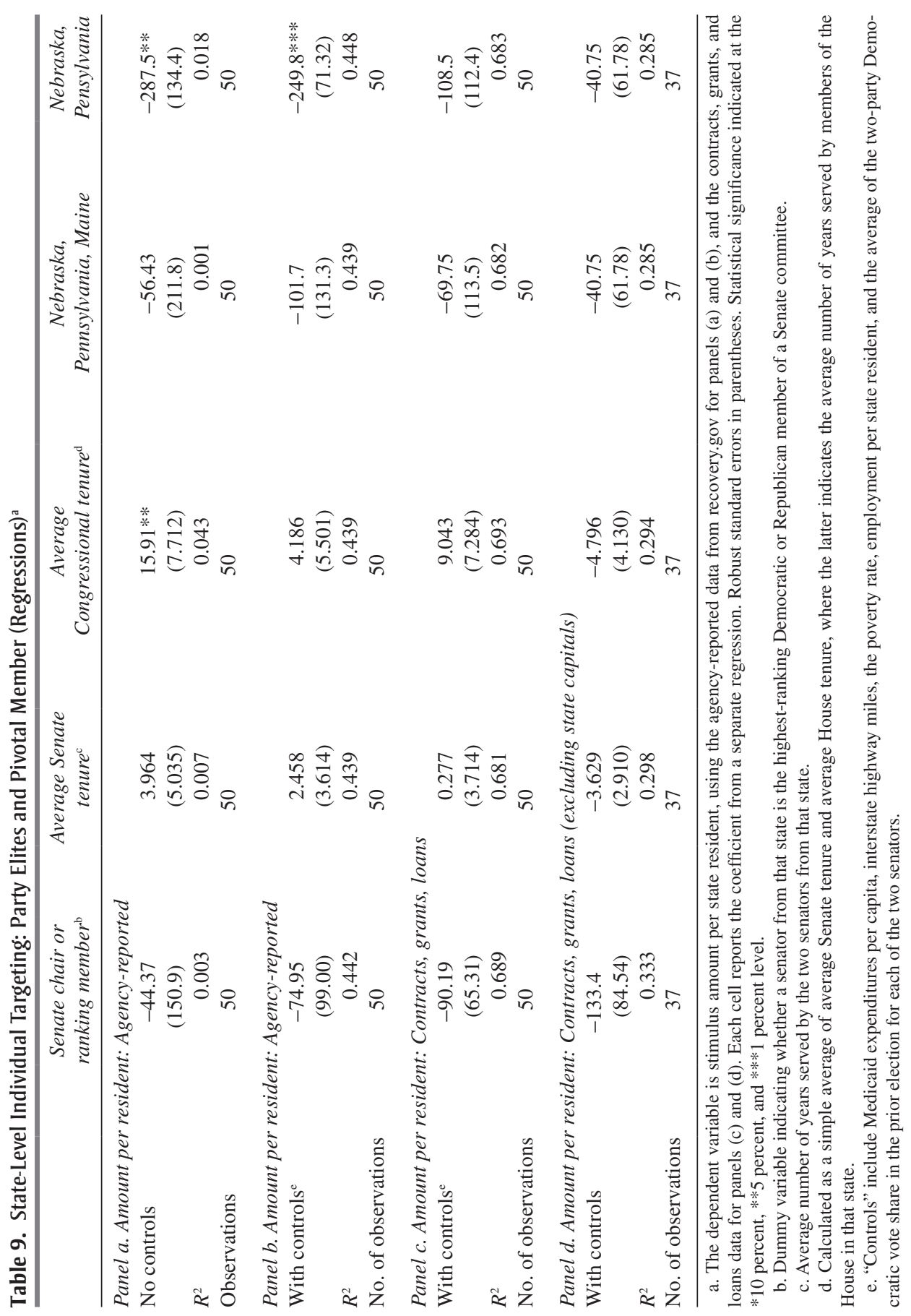


Congress. In a median regression, which reduces the influence of outliers, the coefficient on voting against party is $-\$ 49$ per capita and is not statistically significant at conventional levels (results not shown).

Our results in this section, combined with our results from section IV.E., indicate that ARRA funding was not targeted toward or against influential members of Congress. This is true whether one considers individuals who were in powerful positions in Congress, those pivotal for the vote outcome, or those who defied their party.

\section{Interpretations and Implications for Future Policy}

To summarize our findings, we find little to no evidence of positive targeting of ARRA funds toward powerful individuals in Congress. We also find only limited targeting in favor of the party that held the majority in both chambers of Congress as well as the presidency. Additionally, we find no targeting of funds toward districts that had large increases in unemployment. Nonetheless, we do find that districts with high levels of employment and with a high poverty rate received more funds, though we do not find the same correlations across states.

Our findings that party leaders, swing districts, and ideological moderates did not receive more funding and that defiers did not suffer a clear penalty may not be surprising to close political observers. This is especially so given that contracts, grants, and loans were allocated based on either formulas or competitive grants. Funding formulas are intentionally coarse instruments for the purposes of limiting politically motivated geographical targeting. At the same time, since formula money is allocated by state governors, it is possible to a limited degree for Congress to target particular districts in small states by mandating spending in poor areas, urban areas, rural areas, areas with large highway systems, and in other similar ways. Similarly, while the competitive bidding process limits the ability to target specific areas, the choice of projects still allows a degree of discretion and thus influence.

Moreover, while targeting individual districts would have been difficult, the bill could have easily used funding formulas and even competitive grants to tilt money strongly toward more Democratic states. The spatial outcome for the ARRA spending stands in stark contrast to findings about the other large fiscal stimulus in U.S. history: Roosevelt's New Deal. Fishback, Kantor, and Wallis (2003) document that although New Deal loans were not politically targeted or targeted to high-unemployment areas, grants were targeted both to high unemployment areas and to swing-district 
supporters of Roosevelt in the prior presidential campaign. In this section, we discuss some possible explanations for the limited geographic targeting in the ARRA bill, and we consider why the outcome may have been different during the New Deal era.

One possible explanation for our results is that the spatial allocation reflected the desires of the administration and Congress. As its name suggests, the bill had two components: recovery and reinvestment. While some parts of the bill (such as Unemployment Insurance, Supplemental Nutrition Assistance Program, and Medicaid) were focused on recovery or at least on relief, the CGL component was more focused on reinvestment. Certainly, automatic stabilizers, for example, are well targeted to those with a high propensity to consume out of income and those in or at risk of falling into poverty. Perhaps, then, the spatial allocation of CGL funds reflected the variation in local need for public goods and services rather than the need for jobs.

However, even though other parts of the bill were better targeted, we find it unlikely that the allocation of CGL funds was what the administration would have preferred in the absence of political constraints. In January of 2009, the unemployment rate in California was 9.7 percent and rising rapidly, and the unemployment rate in Michigan was 11.4 percent; however, the unemployment rate in North Dakota was 3.9 percent. Many schools and highways needed to be rebuilt, and it would not have been particularly difficult to use the severity of the business cycle in an area as a factor in allocating funds. We think a more plausible argument is that there are certain trade-offs that arise when greater targeting in fiscal policies is allowed, and the administration's relatively nontargeted approach reflected constraints and not preferences.

Moreover, fine-grained geographic targeting leads to a number of costs. First, there may be increased delays in project selection due to bargaining between legislators, something that runs counter to rapid enactment in the face of a major economic crisis. For example, when Congress tried to set aside a portion of the Medicaid money for high-unemployment areas, the Senate opted for a lower percentage than the House, and this caused delay in bargaining in the conference committee. Second, such discretion may lead to precisely the type of political opportunism that is both predicted by theories of legislative politics and at least partly confirmed by the New Deal experience. Such opportunism could have delegitimized a piece of legislation that was already quite controversial and under substantial public scrutiny. For these reasons, political constraints-both real or perceivedmay have prevented the administration from engaging in a more targeted 
approach, so that instead it favored the use of funding formulas and competitive bidding.

In a majoritarian system, where politicians gain reelection in part by providing funds to their districts, funding formulas limit the degree to which politicians are able to do so. Starting with the Federal Aid Road Act of 1916, Congress increasingly used formulas to allocate federal funds. Besides attempting to reduce graft, Congress introduced formulas to allocate funds in a more streamlined fashion, allowing it first to decide on the level of funding and then to delegate the disbursement of those funds. Formula funding allowed Congress to retain control over what types of projects are funded while bypassing bargaining over the spatial distribution of expenditures that politicians may be particularly interested in. Over time, the use of formulas has become more prevalent. In addition to allowing for timely passage of legislation, channeling money through existing programs in this way has also provided a method for ensuring that funds are spent quickly, a goal that was a priority for this particular piece of legislation.

However, while a relatively nontargeted approach has merits both in reducing the possibility of graft and in possibly expediting the pace of legislation, it comes with costs. In particular, it reduces lawmakers' ability to target based on economic as well as political considerations. It is noteworthy that while the fiscal stimulus in the New Deal may have provided greater awards to swing districts, it also channeled more money to areas of higher unemployment. The good news is that political constraints since that era appear to have made fiscal policy more politically neutral; the bad news is that those constraints may have also reduced countercyclical efficacy.

This has a number of implications for future stimulus bills. First, it means that the components of a policy that are better targeted, such as automatic stabilizers, are quite important, and it may be useful to put greater weight on these. At the same time, besides automatic stabilizers, there are economically sensible reasons to increase public goods provision as part of countercyclical policy, as discussed by J. Bradford DeLong and Lawrence Summers (2012). The relevant hurdle rate for such public-goods projects effectively falls, and an optimal fiscal policy should likely include an expansion in the funding of such projects. However, it should be possible to include local area unemployment rates, or other transparent measures of excess capacity, as a factor in the funding allocation for contracts, grants, and loans. Such an approach would combine the virtues of a more rulesbased policy regime with some of the gains from a more targeted variant of stimulus policy. Had we found that the political process generated 
sufficient demand for added funding in harder-hit areas, the need for such an explicit rule would not arise. However, that is not what we found, suggesting that the inclusion of local excess capacity measures in funding formulas is likely to have a substantial payoff.

Moreover, we note that in the ARRA stimulus the government relied on already existing funding formulas to disperse the funds. This means the time for updating formulas-in order to better accommodate the objectives of countercyclical fiscal policy-is probably now, before the next crisis hits. Of course, this presupposes understanding how to create new legislative norms.

\section{Conclusion}

In this paper, we have looked at the spatial distribution of ARRA funds, both to assess how the bill was targeted economically and politically and as a window for evaluating theories of political economy. We find that the funds were distributed relatively equally across states. Moreover, dropping a small number of outlier districts that each received money for a particular large project, we find that funds were distributed relatively equally across congressional districts as well. We find no evidence that funds were funneled toward powerful or pivotal legislators, nor do we find that funds were withheld by parties to punish members of Congress who defied them. We do find that urban Democratic districts received a moderately higher amount of funding per capita, although most of this gap between Republicans and Democrats disappears when we control for a small number of district or state characteristics that appeared in the formulas used to allocate funds.

We also find that formulas based upon welfare programs administered at the state level are very useful in explaining cross-state variation in funding; poverty rates and employment, which also are pervasively used in federal formulas, are strongly predictive of the cross-district variation. Comparing the targeting of discretionary funds under ARRA with that under New Deal legislation, we find the two episodes bear little resemblance. Grants under the New Deal appear to have been targeted both to higher unemployment areas as well as to swing district supporters of President Franklin Roosevelt. The reduced political and cyclical targeting in the ARRA may reflect a more rules-based environment today compared to the 1930s, and it may also explain the lower amount of variation across space in federal transfers and loans. We hope that future stimulus policies will increase countercyclical targeting by explicitly using measures of local unemployment and 
excess capacity as part of the allocation of contracts, grants, and loans. This was done in the allocation of Medicaid funds already in ARRA.

We view our findings and their contrast with the empirical literature on targeting in the Great Depression as evidence of a shift in social norms over the allocation of federal funds. However, we would like to see more conclusive evidence on the role of social norms. More broadly, we see our findings as a call for continued empirical research on the distribution of funds. If there has been a large shift in norms, have norms within the legislature shifted? Or does the norms shift lie in the public? Alternatively, has the presence of pork lessened over time due to greater coverage of politics in the media (Levitt and Snyder 1995)? These are questions that we hope empirical political economists will address.

ACKNOWLEDGMENTS We thank Bryan Hardy, Kyle Meng, Ruchita Tiwary, Sebastién Turban, and Laurence Wilse-Samson for excellent research assistance, and the Institute for New Economic Thinking for generous financial support. In addition, we thank Allan Drazen, Peter Orszag, Brian Scholl, Erik Snowberg, John Wallis, and the editors for detailed comments. Any mistakes are our own. 


\section{References}

Albouy, David. 2013. "Partisan Representation in Congress and the Geographic Distribution of Federal Funds." Review of Economics and Statistics 95, no. 1: 127-41.

Baron, David P. 1991. "Majoritarian Incentives, Pork Barrel Programs, and Procedural Control." American Journal of Political Science 35: 57-90.

Berry, Christopher R., Barry C. Burden, and William Howell. 2010. "The President and the Distribution of Federal Spending." American Political Science Review 104: 783-99.

Cohen, Lauren, Joshua Coval, and Christopher Malloy. 2011. "Do Powerful Politicians Cause Corporate Downsizing." Journal of Political Economy 119, no. 6: 1015-60.

Conley, Tim, and Bill Dupor. 2013. "The American Recovery and Reinvestment Act: Solely a Government Jobs Program?” Journal of Monetary Economics 60, no. 5: 535-49.

Cox, Gary W., Thad Kousser, and Matthew D. McCubbins. 2010. "Party Power or Preferences? Quasi-Experimental Evidence from American State Legislatures." Journal of Politics 72, no. 2: 799-811.

Dahlberg, Matz, and Eva Johansson. 2002. "On the Vote-Purchasing Behavior of Incumbent Governments.” American Political Science Review 96, no. 1: 27-40.

DeLong, J. Bradford, and Lawrence H. Summers. 2012. "Fiscal Policy in a Depressed Economy." Brookings Papers on Economic Activity, Spring: 233-97.

De Rugy, Veronique. 2010. “Stimulus Facts_-Period 2.” Working Paper, Mercatus Center, George Mason University.

Dube, Arindrajit, Ethan Kaplan, and Ben Zipperer. 2014. "Heterogeneous Effects of Fiscal Expenditure: Local Evidence from the ARRA Bill." Working Paper, University of Maryland (http://econweb.umd.edu/ kaplan/stimulus_effects.pdf).

Feyrer, Jim, and Bruce Sacerdote. 2011. "Did the Stimulus Stimulate? Real-Time Estimates of the Effects of the American Recovery and Reinvestment Act." NBER Working Paper 16759. Cambridge, Mass.: National Bureau of Economic Research.

Fishback, Price, Shawn Kantor, and John Wallis. 2003. "Can the New Deal's Three $R \mathrm{~s}$ Be Rehabilitated? A Program-by-Program, County-by-County Analysis." Explorations in Economic History 40: 278-307.

Gimpel, James, Frances Lee, and Rebecca Thorpe. 2013. "Geographic Distribution of the Federal Stimulus of 2009." Political Science Quarterly 127, no. 4: 567-95.

Grunwald, Michael. 2012. The New New Deal: The Hidden Story of Change in the Obama Era. New York: Simon and Schuster.

Inman, Robert. 2010. "States in Fiscal Distress.” NBER Working Paper no. 16086. Cambridge, Mass.: National Bureau of Economic Research.

Johnson, David S., Jonathan A. Parker, and Nicholas S. Souleles. 2006. "Household Expenditure and the Income Tax Rebates of 2001." American Economic Review 96, no.: 1589-610. 
Knight, Brian. 2005. "Estimating the Value of Proposal Power." American Economic Review 95: 1639-52.

Larcinese, Valention, Leonzio Rizzo, and Celia Testa. 2006. "Allocating the U.S. Federal Budget to the States: The Impact of the President." Journal of Politics 68, no. 2: 447-56.

Levitt, Steven D., and James M. Snyder. 1995. "Political Parties and the Distribution of Federal Outlays." American Journal of Political Science 39: 958-80.

Lindbeck, Assar, and Jurgen Weibull. 1987. "Balanced Budget Redistribution and the Outcome of Political Competition." Public Choice 52: 273-97.

McCarty, Nolan, Keith T. Poole, and Howard Rosenthal. 2001. "The Hunt for Party Discipline in Congress." American Political Science Review 95: 673-87.

- 2006. Polarized America: The Dance of Ideology and Unequal Riches. MIT Press.

- 2013. Political Bubbles: Financial Crisis and the Failure of American Democracy. Princeton University Press.

Nakamura, Emi, and Jon Steinsson. (2014). "Fiscal Stimulus in a Monetary Union: Evidence from U.S. Regions.” American Economic Review 104(3), 753-92.

Shoag, Daniel. 2010. "The Impact of Government Spending Shocks: Evidence on the Multiplier from State Pension Plan Returns." Unpublished working paper.

Shor, Boris. 2006a. "Presidential Power and Distributive Politics: Federal Expenditures in the 50 States, 1983-2001." Working Paper, Princeton University (http://www.princeton.edu/csdp/events/Shor102104/Boris1004.pdf).

_ 2006b. "The Weak Leviathan? Testing Partisan Theories of Political Influence on Defense Procurement in Congressional Districts: 98th-102nd Congress." Unpublished Working Paper, Princeton University.

Silver, Nate. 2010. "Study Claiming Link between Stimulus Funding and Partisanship Is Manifestly Flawed." Five Thirty-eight (blog), April 1 (http://www. fivethirtyeight.com/2010/04/study-claiming-link-between-stimulus.html). 


\section{Comments and Discussion}

\section{COMMENT BY}

PETER R. ORSZAG Christopher Boone, Arindrajit Dube, and Ethan Kaplan have done a compelling job in analyzing the variation in the discretionary component of the American Recovery and Reinvestment Act (hereafter the "stimulus bill") and finding that the pattern of spending per resident across congressional districts and across states does not appear to conform to a variety of traditional political economy theories. As someone who was directly involved in the legislative process associated with the stimulus bill, I am not surprised by these findings.

A core motivation behind the stimulus bill was to have it take effect rapidly, given the dire condition of the economy at the time. Indeed, we now know the situation was even worse than understood at the time. For example, the Blue Chip economic forecast released on December 10, 2008, suggested the economy was contracting that quarter at about a 4 percent seasonally adjusted annualized rate. GDP was actually falling at about twice that rate. Similarly, that same December 2008 Blue Chip forecast suggested that during the first quarter of 2009 GDP would decline by about $2 \frac{1}{2}$ percent; the reality was again twice that (CEA 2014, table 3-1). Put simply, the incoming economics team at the White House knew that stimulus was urgent—and in retrospect that urgency was more than justified. ${ }^{1}$

1. Not that policymakers got everything right (myself very much included in being wrong). The basic design of the stimulus bill involved an emphasis on being "temporary, targeted, and timely." That design reflected a forecast and associated policy error: along with forecasts from other government agencies such as the Fed and the Congressional Budget Office (CBO), the Administration's economic forecasts and also its policy stances did not adequately reflect the possibility of an L-shaped rather than a V-shaped recovery. In retrospect, it would have been relatively inexpensive to have tied continuation of various components of the stimulus bill to cyclical indicators like the unemployment rate-which would 
In this context, policymakers were highly motivated to avoid the "inside lag" curse that has historically undermined the effectiveness of discretionary fiscal policy interventions. As Federal Reserve Board Governor Ned Gramlich put it, "For fiscal policy, the time between recognition and action is long in parliamentary countries, seemingly interminable in the United States... At best this component of the inside lag for U.S. discretionary fiscal policy is about a year, already longer than the average recession, and the lag can be substantially longer than that if the relevant action is at all controversial" (Gramlich 1999). Those types of timing issues caused Alan Blinder to write in 2004 that "at least in the United States, long political lags may be the most cogent argument against discretionary fiscal policy" (Blinder 2004, p. 8).

From this perspective, the stimulus bill was a resounding success. In December 2008, the Obama transition team proposed the overall scope and elements of the stimulus. President Obama was inaugurated on January 20, 2009, and on January 26 Representative David Obey got the legislative ball on the stimulus formally rolling by introducing HR1. The final legislation was signed just 3 weeks later, on February 17. All told, it took only about 2 months from initial proposal to the signing ceremonya dramatic counterexample to the general concern that Edward Gramlich and Alan Blinder properly highlight based on previous fiscal policy episodes.

To enact legislation that quickly, the only choice was to rely on simple, existing approaches to allocating the funds. Optimizing the allocation, to achieve either political or economic objectives like the ones examined by Boone, Dube, and Kaplan, would unacceptably slow down the process and thereby not be optimal from either perspective given the urgency of the situation. The result was that the funds were distributed relatively equally across states and districts.

then have avoided the subsequent legislative wrangling and unnecessary fiscal drag in 2011 and 2012. For example, in January 2009, the CBO projected the 2012 unemployment rate to be 6.8 percent. In reality, the unemployment rate averaged 8.1 percent in 2012 . A policy of continuing in full certain payments (such as the extended and expanded unemployment benefits or the state fiscal assistance contained in the stimulus bill) as long as the unemployment rate remained over a certain threshold (say, 7.5 percent) and then phasing the payments out as the unemployment rate declined to a lower threshold would have carried a relatively small score from CBO (which would have assigned a cost based on the probability mass associated with unemployment being above the trigger thresholds). Policy analysts should give more thought to the design (for example, whether one should use the unemployment rate or the employment-population ratio) of such temporary automatic stabilizers so that they could be easily incorporated into future discretionary spending actions similar to the stimulus bill should the need arise. 
Figure 1. State Population and Total CGL (Stimulus) Spending, All States

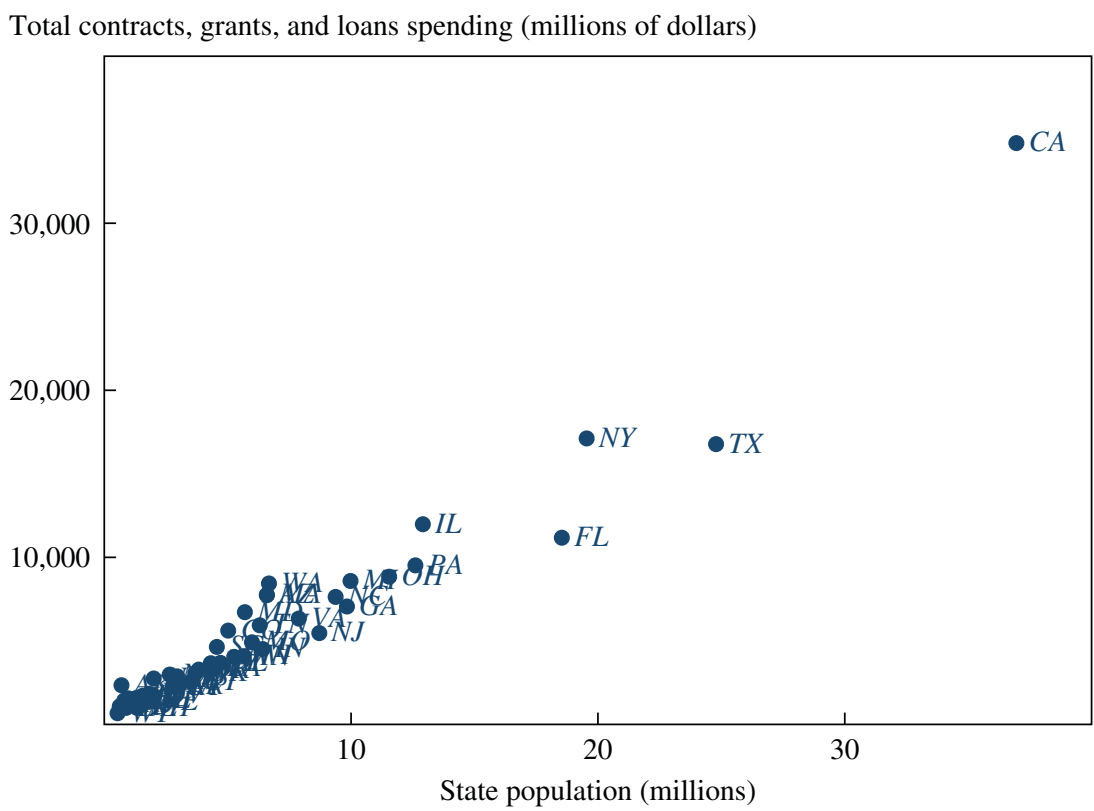

Source: Recovery.gov.

For example, my figure 1 shows a scatterplot of the discretionary spending examined by the authors, by state and the state populations. A simple regression of these variables shows that across states, population alone explains almost 95 percent of the variation in total discretionary spending. That is precisely what one would expect from a rough-and-ready approach intended to avoid the inside lag problem; speed meant relying on existing formulas, and most of the formulas for discretionary spending allocations give a substantial weight to population.

Yet the paper's authors focus their analysis disproportionately on spending per resident, which is similar in spirit to examining the residuals that make up the other 5 percent of the variation in total spending in the figure. In particular, the primary focus of the analysis in the paper is spending per resident across congressional districts, which in turn raises another issue: that the House was not the binding political constraint. ${ }^{2}$

2. The authors note that when dummy variables are included for 17 district outliers (driven largely by competitive grants that happened to be won by entities in the districts), the bulk of the variation across congressional districts is driven effectively by population, which is similar to the results at the state level. 
On January 20, 2009, there were 256 Democrats in the House and 178 Republicans; and the rules of the House meant that with full Democratic support, the House would pass the stimulus bill. The situation in the Senate was much different, however. There were officially 57 Democrats and 41 Republicans; but the rules of the Senate, such as the filibuster procedure, meant that some Republican votes would be necessary in order for the Senate to pass the bill.

Not surprisingly, therefore, most of the administration's attention was on how to get the bill through the Senate. That fact did not go unnoticed in the House. Several administration officials (including me) were the target of much displeasure surrounding the perceived (and real) focus on the Senate. As Representative Charlie Rangel of New York has been quoted as saying, the House "was way beyond frustration. Whichever senator wants to be wooed, we're just supposed to accept it" (Grunwald 2012, p. 232)

An interesting political question, therefore, is how the swing votes in the Senate decided to use their leverage. For example, Senator Olympia Snowe of Maine used her influence to insist that a patch for the Alternative Minimum Tax be included within the "total" for the stimulus bill. ${ }^{3}$ Senator Susan Collins of Maine curtailed a proposal for school construction. ${ }^{4}$ And Senator Arlen Specter of Pennsylvania insisted on $\$ 10$ billion in temporary funding for the National Institutes of Health. ${ }^{5}$ None of these uses of political capital by the senators who held the legislation's fate in their hands (because their votes were the marginal ones necessary for enactment) generated disproportionate benefits for their home states. Instead, the swing senators appear to have been motivated by other policy considerations.

In sum, the binding political constraint on the stimulus legislation was the Senate, and the urgency of the situation limited the maneuvering room for deviating from simple rules, with the result that the vast majority of the geographical variation in spending across the United States can be explained simply by population. In that context, it is perhaps not particularly surprising that the authors' attempt to find strong evidence of various political economy theories by examining per-resident spending across congressional districts finds little such evidence.

3. "Senate Passes $\$ 838$ Billion Stimulus Bill.” Associated Press report dated February $11,2009$.

4. "Senate Cuts School Construction from Stimulus Plan." Architectural Record, February 6, 2009.

5. "Specter, a Fulcrum of the Stimulus Bill, Pulls Off a Coup for Health Money." New York Times, February 13, 2009. 


\section{REFERENCES FOR THE ORSZAG COMMENT}

Blinder, Alan S. 2004. "The Case against the Case against Discretionary Fiscal Policy.” Working Paper no. 100. Princeton University, Center for Economic Policy Studies.

Council of Economic Advisers (CEA). 2014. "The Economic Impact of the American Recovery and Reinvestment Act." Chapter 3 in The Economic Report of the President-Transmitted to Congress, March 2014. Washington.

Gramlich, Edward M. 1999. "A Stabilization Policy Strategy.” Remarks before the Wharton Public Policy Forum Series, Philadelphia, April 22 (http://www. federalreserve.gov/boarddocs/speeches/1999/199904222.htm).

Grunwald, Michael. 2012. The New New Deal. New York: Simon \& Schuster.

\section{COMMENT BY}

ERIK SNOWBERG Very little research has sought to test theories of distributive politics. In the United States, this is largely due to the difficulty of accurately measuring the level of spending across different Congressional districts.

This paper, by Christopher Boone, Arindrajit Dube, and Ethan Kaplan, reminds us why such tests, despite their practical difficulty, are important. The finding that canonical models of distributive politics fail to provide useful predictions about the allocation of spending in the American Recovery and Reinvestment Act (ARRA) is striking and significant. ${ }^{1}$ It would be too easy, as the other discussant has done, to make excuses for these models by claiming that the authors have missed some important trees by looking at the forest of data, or to simply dismiss these models as irrelevant. What is more difficult, if the authors' conclusions are representative of general phenomena, is to use them to refine our models.

Here I will argue that incorporating the negotiating skills of legislators into existing models can go a long way toward understanding the authors' findings. Although much of the following logic is easily formalized, it is essentially a story that gives a passable reading of the facts rather than a theory. ${ }^{2}$

1. The fact that normative economic theories fail to provide a useful guide to understanding implemented policy should come as no surprise to anyone familiar with either the public choice literature or legislators themselves.

2. The idea that skills, or "valence," may be an important component of political economy models dates back to Stokes (1963), although research in this vein has tended to focus on the electoral, rather than policy, consequences of valence (see Groseclose 2001). More recent work has put more structure on these skills (Besley 2007), often in an attempt to explain incompetent or corrupt politicians (Mattozzi and Merlo 2008; Bernheim and Kartik 2014). 
NEGOTIATING SKILLS. While there are many skills that would serve a legislator well, it is sufficient to focus on the ability to negotiate transfers for one's legislative district. If voters value transfers to their districts highly — and by all accounts, in the United States they do- then they should elect the most skilled candidate they can. Some states and districts happen to have very skilled candidates to choose from, but not all can be lucky enough to have an Alfonse D'Amato (R-NY), Robert Byrd (D-WV), or Don Young (R-AK) standing for office. A first pass assumes that these skills are randomly distributed among candidates, and thus among districts. Moreover, the variance of skills in the legislature would be increased by imperfect information about the precise skill levels of candidates standing for office. This comports well with the authors' finding that although there is a large amount of variance in transfers received by a district under the ARRA, very little of it can be explained by canonical models of distributive politics.

How much do negotiating skills matter? Under the United States Constitution, Congress is free to structure most aspects of lawmaking. In equilibrium, the proportion of funds distributed by negotiation versus the proportion distributed (relatively evenly) by formulas should thus accord with the preferences of some pivotal legislator. ${ }^{3}$

If there is some disutility associated with the effort entailed in negotiating, the pivotal legislators' preferences will be proportional to the skill gap between themselves and the average legislator. If the pivotal legislator is more skilled than average, he or she would prefer a greater portion of funds to be distributed by negotiation, whereas if the pivotal legislator possesses subpar skills, he or she would prefer that all funds be allocated by formulas.

This observation may be useful in explaining the gradual embrace of funding formulas pointed out by the authors. Between the New Deal and today, Congress has become increasingly professionalized. This, in conjunction with the decline of both political machines in northern cities and of the "solid south," would have led to a tightening of the distribution of skills in Congress. According to the logic above, this would lead to an increasing proportion of funds distributed by formulas.

ROLE OF CONGRESSIONAL LEADERSHIP. It is likely that members of the Congressional leadership have an increased capacity to negotiate funds for their

3. Following Downs (1957), the legislator with the median level of skills is an attractive candidate for the pivotal legislator. However, given leadership's control of the legislative agenda and superior skill, especially in the House, the pivotal legislator may be significantly more skilled than the median-skilled legislator (Cox and McCubbins 2005). This is easily modeled as a weighted voting procedure where legislators in the leadership, or with greater skill, receive greater weights. 
districts. What, then, should we make of the authors' finding that members of the Congressional leadership seemed to have received no more funds from the ARRA than the average Congressmember? This could be a failure of the logic that has taken us to this point, but in keeping with the focus of this discussion, I prefer to think of it arising from an errant assumption in the canonical model of legislative bargaining.

In particular, David Baron and John Ferejohn (1989) assume that legislators only care about transfers to their own districts. This assumption is of solid provenance, rooted in David Mayhew's (1974) characterization of members of Congress as "single-minded seekers of reelection." But where might the minds of Congress members reasonably assured of reelection wander? Many members in "safe" districts aspire to the leadership, and those that succeed likely possess greater skill. But earning and maintaining a leadership position requires doing favors for members of the leader's caucus. If the leadership devotes its "surplus" skills to securing funds for important members of its caucus, then we would expect to see the leadership receive no more funds than average. This, coupled with the fact that the Democrats ran the House during the writing and passage of the ARRA, may account for the excess spending in Democratic districts. ${ }^{4}$

In conclusion, the results under discussion present a challenge to the canonical models of political economy. I have presented one possible way of accommodating these results. However, the additional element focused on here-negotiating skill-may not be the most important thing missing from these theories. On the other hand, it is possible that I have not pushed this perspective far enough - for example, areas with more economic activity also have higher levels of human capital. Thus, these districts may have a pool of potential candidates with greater political skills, leading to more transfers, in accordance with the authors' findings. ${ }^{5}$

\section{REFERENCES FOR THE SNOWBERG COMMENT}

Baron, David P., and John A. Ferejohn. 1989. "Bargaining in Legislatures." American Political Science Review 83, no. 4:1181-206.

4. Depending on the specification, this excess ranges from a statistically insignificant 6 percent of the average transfer to 20 percent of the average. The authors seem to view the latter number as relatively small. However, in order to fairly judge the magnitude of this excess, it should be compared to the maximum attainable excess using funding formulas, which defined the space of negotiation for the ARRA.

5. This is the assumption underlying the analysis in Mattozzi and Snowberg (2014), the model upon which the logic here is built. 
Bernheim, B. Douglas, and Navin Kartik. 2014. "Candidates, Character, and Corruption." American Economic Journal: Microeconomics 6, no. 2: 205-46.

Besley, Timothy. 2007. Principled Agents? The Political Economy of Good Government. Oxford University Press.

Cox, Gary W., and Mathew D. McCubbins. 2005. Setting the Agenda: Responsible Party Government in the U.S. House of Representatives. Cambridge University Press.

Downs, Anthony. 1957. An Economic Theory of Democracy. New York: Harper Collins.

Groseclose, Tim. 2001. “A Model of Candidate Location When One Candidate Has a Valence Advantage." American Journal of Political Science 45, no. 4: 862-86.

Mattozzi, Andrea, and Antonio Merlo. 2008. "Political Careers or Career Politicians?" Journal of Public Economics 92, no. 3: 597-608.

Mattozzi, Andrea, and Erik Snowberg. 2014. "The Right Type of Legislator." Mimeo. California Institute of Technology.

Mayhew, David R. 1974. Congress: The Electoral Connection. Yale University Press.

Stokes, Donald E. 1963. "Spatial Models of Party Competition.” American Political Science Review 57, no. 2: 368-77.

GENERAL DISCUSSION Alan Blinder found himself persuaded by discussant Peter Orszag's critique of the paper, but wanted to defend the authors for considering the element of political braggadocio in general. Several congressional staffers had told Blinder they had written the American Recovery and Reinvestment Act (ARRA) themselves-perhaps an exaggeration but probably a claim with some truth. Following standard political economy theory, he said, one would expect the House version of the bill to put more money into districts with members serving on the Ways and Means or Appropriations committee or, generally, in the House leadership. That the authors' analysis did not find such effects was a surprising and, to him, heartening finding.

Henry Aaron said that while he accepted Orszag's narrative of what transpired politically with ARRA, namely that the White House concentrated on persuading the Senate to get it passed quickly, might one not also assume that bargaining was going on among elected officials, including in the House, about the distribution? If that were the case, the appropriate universe to examine would not be the discretionary spending categories but the relative sizes of the various elements of ARRA, which may have been bargained over. After all, one could have had more or 
less tax cuts, and one could pour more or less money into unemployment insurance or food stamps or even Medicaid.

Justin Wolfers thought the paper demonstrated the failure of a major branch of social science, since the authors had thrown at the data nearly every standard political economy model as well as the standard economic models, and still they came up with basically none of the predicted results. He agreed with Orszag that the analysis would do better to examine particular senators, although even then the same models would fail. Senator Arlen Specter, for example, was not trying to get himself reelected or to get others elected at the time but only seeking more funding for the National Institutes of Health. Wolfers wondered whether, alternatively, there might have been something special about the ARRA and whether the standard models would perform better in analyzing other stimulus bills.

Gabriel Chodorow-Reich pointed out that the highway money in the bill actually had to be appropriated by states by the end of 2010 . If it is difficult to find enough projects in high-unemployment areas, then geographic spillovers may justify spending where unemployment is lower. He also questioned whether the goal of responding to high-impact areas should be met by targeted project spending or, instead, through programs like unemployment insurance, food stamps, or welfare. According to the Economic Report of the President, excluding the AMT, about a sixth of the ARRA is in the form of unemployment insurance, food stamps, or TANF payments. The unemployment insurance extensions passed by Congress after the ARRA further shifted the overall spending mix toward harder-hit areas. Chodorow-Reich noted possible trade-offs in targeting certain areas through project aid as opposed to these other measures, such as different effects on labor supply. Did ARRA strike the right balance between those trade-offs, or are there better ways to do it?

Jay Shambaugh recalled how the states' departments of transportation later stated that money that passed through formulas the way some ARRA funds were arranged was easier to spend, that is, it was distributed faster than it would have been through a new process.

Daniel Sichel wondered whether the paper's prior assumptions had been correctly established from the start. The authors seemed to point to the New Deal stimulus as a standard model of political and economicimpact targeting that people expected to see replicated in ARRA. They were surprised to find that we are no longer living in that political world, but were their initial priors reasonable? Until he read Joshua Hausman's paper on veterans' bonuses during the Great Depression, Sichel had thought 
there had not been much fiscal policy practiced during that period. Were there other, more recent fiscal policy episodes in which political targeting was evident? Possibly political targeting should not have been expected and, on the contrary, the way this bill unfolded was just the way it's always been.

Alice Rivlin, echoing Sichel's comment, was surprised by discussant Erik Snowberg's shock at the idea that Congress would want to tie its hands. Congress, in her experience, is fond of tying its hands, in part because the alternative is perpetual fighting, and Congress has learned over the years that fighting is politically costly. The spending formulas themselves are evidence that they wanted to tie their hands, and the paper seemed proof to her that Congress did so quite effectively in 2009. She added that since then, Congress's dedication to this approach has grown even stronger, with earmarks becoming a no-no; in her view, this has been a loss in some respects.

Gary Burtless returned to the topic of ARRA's spending composition and to the fact that the entitlement spending was determined by formula. In some cases, the entitlement stimulus was more generous for states that adopted policies agreeable to the Democratic majority in Congress. $\mathrm{He}$ cited the Medicaid match formula, which was temporarily made much more generous to each state, but only if the state did not make Medicaid eligibility more restrictive and if it continued to make prompt payments to medical providers. Likewise, in order to maximize the value of federal stimulus assistance for unemployment compensation, a state had to liberalize the triggering mechanism for the federal-state Extended Benefit program and change certain eligibility conditions for regular unemployment benefits. States that failed to take these steps could receive federal funding for emergency extensions of unemployment benefits, but they received less federal help than they would have if they had liberalized their regular and Extended Benefit programs. Cumulatively, over the recession, the added federal aid to states that made more generous provision for Medicaid and unemployment insurance could provide states with a great deal of money. Burtless believed that when the Democrats in Congress passed the stimulus package they must have recognized that in party bastions, like Albany and Sacramento, the legislatures were going to make the desired policy changes in order to qualify for the maximum allowable federal assistance.

Gregory Mankiw suggested that since the paper found that a lot of the stimulus was determined by rules after all, another paper deserves to be written, namely to identify what the best rule would be. He did not find 
the idea of targeting stimulus to wherever unemployment was particularly high to be convincing. If this last recession had been a Keynesian-style demand recession and unemployment had simply been higher in some places than in others, that suggestion would make sense, but in fact there were also longer-term structural changes, with growing areas and shrinking areas. It makes little sense to put money into building a lot of infrastructure in a region where unemployment is currently high if the economy there has also been experiencing long-term shrinkage. The places where new infrastructure is needed are actually the growing areas.

Caroline Hoxby raised some red flags regarding how stimulus funds get spent. Even when the federal government does do a good job of targetingapparently maximizing the multiplier-states can undo it, she argued. Not all stimulus money sticks where it hits. She offered an example from her own research on the Pell grant, which was one of ARRA's major funding items. Raising the grant would seem to maximize the multiplier, because the money was directed to low-income students, young people who would spend it rather than saving it. But she had found that this stimulus caused states to take away the same amount of money from universities, dollar for dollar, by reducing appropriations. States also did this in response to other federal grants under ARRA.

Robert Gordon returned to a thought raised by Chodorow-Reich regarding fiscal multipliers. He recalled that in the summer of 2010, Blinder and Mark Zandi wrote a paper rating the effects of an array of multipliers in fiscal stimulus bills and found that the champion multipliers were food stamps and unemployment insurance. They also found that cuts in corporate taxes and personal taxes on the rich ranked at the very bottom. He posed a question to Orszag: Did he think the ARRA had maximized the multiplier, and if not, what were the political constraints preventing that?

Orszag spoke in response to that and several other comments. The ARRA multiplier was not in fact maximized, he said, since many of the spending approaches that would have ranked higher were precluded to obtain political support. If he were to grade the final version of the bill from a multiplier perspective, he would award it a $B$-. Referring to Hoxby's comment, he said the White House understood that sometimes the money does not stick to its target. State fiscal relief had been ranked near the top, and they tried to maximize that, but there they ran into other political economy constraints. On the other hand, given the very rapid two-month inside lag, he felt the multiplier-weighted average was fairly good. He referred everyone to the Economic Report of the President, which he believed did a good job 
of rebutting the claim that the stimulus was completely ineffective, including because states zeroed out the funds' stimulative effect.

Orszag added that in retrospect, the biggest problem with the stimulus was neither the weakness of the multiplier nor the amount of stimulus delivered in the fourth quarter of 2009 but, rather, how little of it was delivered in 2010 and 2011. Since the recession turned out to be an L-shaped rather than a V-shaped scenario, the ex-post temporary and timely targeting was exactly the wrong approach.

He reiterated a point from his prepared comment, that while not every macroeconomist misunderstood the crisis, every macroeconometric model had gotten it wrong, leading policymakers to overlook an option they could have purchased at a very low price, namely to have included conditional extensions of entitlements like unemployment insurance, basing them on the changing state of the labor market. Finally, he said there were also some elements included in ARRA which, while relatively low multipliers at the time, did have some longer-term structural benefits, such as funding for electronic health records, whose rapid adoption, he feels, has contributed to the deceleration in the country's health care costs.

Ethan Kaplan responded to many of the points raised as well. He and his coauthors agree with Orszag both that seeking a short political lag was very important and that the population across states could serve as a powerful predictor of how much money states received. They believe ARRA was probably relatively successful at reducing lag times and that it was definitely successful at fighting pork. What surprised them, however, was that this was different from the way such bills used to be developed.

Nevertheless, Kaplan and his coauthors concluded that this likely was not an economically optimal way to distribute the funds. Simple modifications could be made to formulas that would not cause time to be lost to bargaining or lead to pork-barrel spending but would still target better. While the Administration did not intend all the ARRA money to be targeted to high-unemployment areas, even nontargeted portions like the funds for highway miles were prioritized for places under economic distress as defined by the 1965 highway act. Kaplan felt that targeting through formulas tied to cyclical downturns, as was done in the bill's Medicaid portion, was better. This is why he did not see what would be so difficult about including unemployment insurance.

Responding to Snowberg's comment, Kaplan pointed out that the stimulus's shape was not necessarily just up to legislators, but depended on the Administration as well. President Obama rejected earmarks from the outset and instructed Congress to apply only formula grants and 
competitive grants, and that is how the final bill turned out. In response to Chodorow-Reich, Kaplan said he and his coauthors were not arguing that every dollar should have been spent in the highest-unemployment area, since that could have led to capacity constraints. But they agreed with what most people were arguing, namely that it would have been preferable to put more money into high-unemployment areas than into low-unemployment areas.

Kaplan pointed out that the paper did indeed include some state-level analysis, and said they found very little political influence there. The fact that Maine, Nebraska, and Pennsylvania did not walk away with any excess of funds made this clear. What members of Congress probably did do is alter what types of funding were chosen, as Orszag pointed out and indeed witnessed. The fact that states with pivotal senatorial votes did not receive greater levels of funding was probably due to the rise of formula usage and reflects a shift from politicians fighting over funds for their constituencies to fighting for funds for projects they ideologically support.

Finally, Kaplan noted that while many Republican governors initially said they were going to refuse ARRA funds, in the end all 50 states accepted most funds, including one state that was ordered by the courts to do so. If their study had taken account of the money rejected by Republican governors, and therefore missing from many Republican districts, he said, it would have shown even less targeting to Democrats than the paper reported. 
